\title{
Volume and Surface Nucleation of Crystals in Glass Based on Blast-Furnace Slag
}

\author{
Galina A. Sycheva \\ Grebenshchikov Institute of Silicate Chemistry, Russian Academy of Sciences, St. Petersburg, Russia \\ Email: Sycheva_galina@mail.ru
}

How to cite this paper: Sycheva, G.A. (2017) Volume and Surface Nucleation of Crystals in Glass Based on Blast-Furnace Slag. Journal of Crystallization Process and Technology, 7, 11-47. https://doi.org/10.4236/jcpt.2017.72002

Received: January 31, 2017

Accepted: April 27, 2017

Published: April 30, 2017

Copyright $\odot 2017$ by author and Scientific Research Publishing Inc. This work is licensed under the Creative Commons Attribution International License (CC BY 4.0).

http://creativecommons.org/licenses/by/4.0/

\section{(c) (i) Open Access}

\begin{abstract}
Using differential thermal analysis, X-ray phase analysis, electron microscopy, and optical microscopy, the nucleation of crystals in glass obtained by blending metallurgical slag with silicon dioxide has been studied. The type of crystallization (homogeneous or heterogeneous, volume or surface) is revealed for each of nine compositions of synthesized glass. It is shown that the first crystalline phase in a volume crystallizing glass is perovskite $\left(\mathrm{CaO} \cdot \mathrm{TiO}_{2}\right)$; in this phase a nucleation of the main phase occurs: melilite (solid solution of gehlenite $2 \mathrm{CaO} \cdot \mathrm{Al}_{2} \mathrm{O}_{3} \cdot \mathrm{SiO}_{2}$ in akermanite $\left.2 \mathrm{CaO} \cdot \mathrm{MgO} \cdot 2 \mathrm{SiO}_{2}\right)$. The fundamental characteristics of homogeneous (for a catalizing phase, perovskite) and heterogeneous (for a catalyzed phase, melilite) of crystallization are determined: the steady state nucleation rate $I_{\mathrm{st}}$, time of unsteady state nucleation $\tau$, crystal growth rate $U$, and activation energy of frictional flow. The temperature dependences of $I_{\mathrm{st}}, \tau$, and $U$ are obtained. The kinetics of the crystallization of glass is studied and the rates of the surface crystal growth are determined in the glass of nine compositions. The influence of grinding the particles of the original glass on the sequence of deposition of the crystalline phases was studied. Practical recommendations are presented for the use of blast-furnace slag as a raw material for the synthesis of glass and their further utilization.
\end{abstract}

\section{Keywords}

Glass Based on Blast-Furnace Slag, Volume Nucleation, Catalyzed Volume Nucleation, Surface Crystal Growth and Nucleation

\section{Introduction}

The crystallization ability of oxide glass has been widely studied; however, the publications on this topic are mainly devoted to studying mass crystallization. Crystalline compounds of glass-forming systems, for which the fundamental nucleation characteristics are determined for volume homogeneous and/or hetero- 
geneous nucleation and which are the bases for the development of a theory of a new phase origination in condensed systems, are listed in [1]. Currently we know of 14 crystalline compounds, for which the temperature dependence of the steady and unsteady crystal nucleation in the bulk nucleation were studied. They are: $\mathrm{Li}_{2} \mathrm{O} \cdot 2 \mathrm{SiO}_{2}, \mathrm{Li}_{2} \mathrm{O} \cdot \mathrm{SiO}_{2}, \mathrm{Na}_{2} \mathrm{O} \cdot 2 \mathrm{CaO} \cdot 3 \mathrm{SiO}_{2}, 2 \mathrm{Na}_{2} \mathrm{O} \cdot \mathrm{CaO} \cdot 3 \mathrm{SiO}_{2}, \mathrm{BaO} \cdot 2 \mathrm{SiO}_{2}, \mathrm{CaO} \cdot \mathrm{SiO}_{2}$, $\mathrm{Na}_{2} \mathrm{O} \cdot \mathrm{SiO}_{2}, \quad \mathrm{Na}_{2} \mathrm{O} \cdot 2 \mathrm{SiO}_{2}, \quad \mathrm{MgO} \cdot \mathrm{Cr}_{2} \mathrm{O}_{3}, \quad \mathrm{CaO} \cdot \mathrm{MgO} \cdot 2 \mathrm{SiO}_{2}, \quad \mathrm{Na}_{2} \mathrm{O} \cdot \mathrm{Al}_{2} \mathrm{O}_{3} \cdot 6 \mathrm{SiO}_{2}$, $2 \mathrm{SnO} \cdot \mathrm{P}_{2} \mathrm{O}_{5}, \mathrm{Na}_{2} \mathrm{O} \cdot \mathrm{ZnO} \cdot \mathrm{P}_{2} \mathrm{O}_{5}, \mathrm{BaO} \cdot \mathrm{B}_{2} \mathrm{O}_{3} \cdot \mathrm{P}_{2} \mathrm{O}_{5}$. The temperature dependences of steady-state nucleation are mainly obtained for the glass of a stoichiometric composition or close to stoichiometry. The greatest attention was paid by researchers to the system $\mathrm{Li}_{2} \mathrm{O}-\mathrm{SiO}_{2}$ because of its practical importance. As the composition becomes complicated and retreats from stoichiometry, the number of works decreases and, therefore, the investigation into the kinetics of volume nucleation in the systems of complicated composition is topical from the scientific point of view.

In choosing a specific object for studies, we were influenced by its practical importance. In recent years, huge volumes of slag wastes have been accumulated in Russia (Table 1), which has harmed the ecological environment in the regions.

The production of one ton of crude iron is accompanied by the formation of 400 to $650 \mathrm{~kg}$ of slag [2]. Earlier, up to 148 million tons of steel was melted annually in our country, 107 million tons of crude iron was melted in 1980, and 107 million tons of rolled metal was melted in 1980 and, hence, no less than 60 million tons of slag was produced annually. According to the state classification, metallurgical slag belongs to technogenic materials, production waste of the fourth class of danger in terms of the harm it does to the environment [3]. One of the work groups designed to use blast-furnace slag is its application as raw

Table 1. Products industry by years in Russia (million tons).

\begin{tabular}{cccc}
\hline Year & Crude iron & Steel & Rolled \\
\hline 1913 & 4,6 & 4,9 & 4 \\
1928 & 3,3 & 4,8 & 3,2 \\
1940 & 14,9 & 18,3 & 13,1 \\
1950 & 19,2 & 27,3 & 18 \\
1958 & 39,6 & 54,9 & 43,1 \\
1960 & 46,8 & 65,3 & 43,7 \\
1961 & 50,9 & 70,8 & - \\
1965 & 66,2 & 91 & 70,9 \\
1970 & 85,9 & 116 & 80,6 \\
1975 & 103 & 141 & 99 \\
1980 & 107 & 148 & 103 \\
1986 & 114 & 161 & 112 \\
1988 & 115 & 163 & 116 \\
\hline
\end{tabular}


material for the production of stone cast items possessing high strength characteristics, abrasive wearability, and resistance to aggressive media [4]-[11].

In this work, we synthesized glass based on slag from the Ural Nizhnetagil Blast Furnace Combinate, which in terms of the content of the main oxides can be attributed to the system $\mathrm{CaO}-\mathrm{MgO}-\mathrm{Al}_{2} \mathrm{O}_{3}-\mathrm{SiO}_{2}$, which possesses a wide range of glass-forming ability that gives the possibility to choose the composition by an immaterial additional blending [11] [12]. In the obtained multicomponent glass, we studied the volume nucleation of crystals according to homogeneous and heterogeneous mechanisms.

\section{Equipment and Techniques of Synthesis and Investigations}

Glass was synthesized in a furnace with silicon carbide heaters at a temperature of $1450^{\circ} \mathrm{C}$. Thermal treatments were performed in SSOL-type electrical shaft furnaces; the temperature could be maintained with an accuracy of $\pm 1^{\circ} \mathrm{C}$. Chemical analysis of slag and glass obtained from them was carried out in the laboratory of analytical chemistry of the Grebenshchikov Institute of Chemistry of Silicates (ICS) of the Russian Academy of Sciences.

To carry out qualitative and quantitative X-ray-phase analysis (XPA), we used an XPA refractometer DRON-2; $\mathrm{Cu} K_{\alpha} \mathrm{X}$-ray-radiation; an operating voltage and current of the tube of $30 \mathrm{kV}$ and $20 \mathrm{~mA}$, respectively; and velocity of counter rotation of $2 \mathrm{grad} / \mathrm{min}$. A differential-thermal analysis (DTA) was carried out on a MOM derivatograph, the crucibles were from platinum, the heating rate was 15 $\mathrm{K} / \mathrm{min}$, the batch mass was $1 \mathrm{~g}$, the galvanometer sensitivity was $1 / 5$, and the reference substance was $\mathrm{Al}_{2} \mathrm{O}_{3}$. The density of glass was measured pycnometrically. Optical microscopy in a reflected light was carried out on a Neophot 32, Carl Zeiss Jena (Germany) microscope. Electron microscopy was carried out on an EM-125 transmission electron microscope using the method of carbon replicas at an accelerating voltage of $75 \mathrm{kV}$.

Glass viscosity near the temperature of vitrification was measured using the method of bending on a viscosimeter developed by V.P. Kluyev and the viscosity of the melts was measured using the method of platinum sphere drawing. The temperature dependences of viscosity were processed using the method of least squares with the help of a standard computer program for finding coefficients $A$, $B$, and $T_{0}$ in the approximation equation using the Vogel-Fulcher-Tamman method [13]:

$$
\lg \eta=A+\frac{B}{T-T_{0}}
$$

The deviation of the calculated values from the experimental ones did not exceed 0.05 units $\log (\eta, \mathrm{dPa} \cdot \mathrm{s})$. The rate of crystal nucleation in glass was determined using the development method. The crystals nucleated in the process of isothermal exposure at low temperature were then grown at a higher temperature of development $T_{\text {dev }}$ to the sizes fixed by an optical microscope and, hence, 
suitable for measuring their diameters and counting their number.

\section{Experimental. Characteristics of Initial Slag}

The chemical analysis of the samples taken from three different pieces of slag is presented in Table 2.

However, we note that the slag is inhomogeneous in composition, and for one and the same slag the composition can vary from one part to another. The main components of all the slag are oxides of silicon, calcium, magnesium, aluminum, and titanium, which in total amount to $94-95 \mathrm{~mol} \%$. Silica is the only glassforming oxide present in the slag. As can be seen from Table 2, slag III contains a greater amount of silica than slag I and II, which are close in terms of the content of all their main components; therefore, in future only slag II was used for the synthesis of glass. The content of oxides-modifiers $\mathrm{MgO}$ and $\mathrm{CaO}$ in slag II and III is similar (42.2 and $44.4 \mathrm{~mol} \%$, respectively) and substantially exceeds the content of silica. The content of alkali oxides in all the slag does not exceed $1.2 \mathrm{~mol} \%$; i.e., the slag can be considered to be without alkali. The content of $\mathrm{Al}_{2} \mathrm{O}_{3}$ and $\mathrm{TiO}_{2}$ in slag I and II (about $24 \mathrm{~mol} \%$ ) exceeds their content in slag III (about $15 \mathrm{~mol} \%$ ) by a factor of 1.5. As is known, although these oxides are not glass-forming, they could play such a role in glass of a complicated composition. The XPA of slag showed the presence of the following compounds in their composition: gehlenite $2 \mathrm{CaO} \cdot \mathrm{Al}_{2} \mathrm{O}_{3} \cdot \mathrm{SiO}_{2}$ (with a temperature of melting of $T_{\text {melt }}$ $\left.=1590^{\circ} \mathrm{C}\right)$, akermanite $2 \mathrm{CaO} \cdot \mathrm{MgO} \cdot 2 \mathrm{SiO}_{2}\left(T_{\text {melt }}=1460^{\circ} \mathrm{C}\right)$, perovskite $\mathrm{CaO} \cdot \mathrm{TiO}_{2}$ $\left(T_{\text {melt }}=1915^{\circ} \mathrm{C}\right.$ ), $\beta$-wollastonite $\mathrm{CaO} \cdot \mathrm{SiO}_{2}$ (at $1125^{\circ} \mathrm{C}$ transfers into pseudowollastonite with $\left.T_{\text {melt }}=1540^{\circ} \mathrm{C}\right)$, and forsterite $2 \mathrm{MgO} \cdot \mathrm{SiO}_{2}\left(T_{\text {melt }}=1895^{\circ} \mathrm{C}\right)$.

Table 2. Chemical composition of initial slag according to the results of the analysis (mol \%).

\begin{tabular}{cccc}
\hline & \multicolumn{3}{c}{ Number of slag } \\
\cline { 2 - 4 } Oxides & $\mathrm{I}$ & $\mathrm{II}$ & Ш \\
\hline $\mathrm{SiO}_{2}$ & 28.93 & 29.29 & 35.69 \\
$\mathrm{Al}_{2} \mathrm{O}_{3}$ & 14.87 & 16.14 & 12.99 \\
$\mathrm{MgO}$ & 11.81 & 11.13 & 7.42 \\
$\mathrm{CaO}$ & 30.17 & 31.10 & 36.98 \\
$\mathrm{TiO}_{2}$ & 9.09 & 8.04 & 2.17 \\
$\mathrm{Fe}_{2} \mathrm{O}_{3}$ & 1.29 & 0.75 & 0.45 \\
$\mathrm{Na}_{2} \mathrm{O}$ & 0.51 & 0.52 & 0.68 \\
$\mathrm{~K}_{2} \mathrm{O}$ & 0.47 & 0.41 & 0.54 \\
$\mathrm{MnO}$ & 0.54 & 0.69 & 0.56 \\
$\mathrm{SO}_{3}$ & 1.23 & 0.13 & 1.27 \\
$\mathrm{~V}_{2} \mathrm{O}_{5}$ & 1.07 & 1.78 & 1.24 \\
$\mathrm{Cr}_{2} \mathrm{O}_{3}$ & 0.02 & 0.02 & 0.01 \\
\hline & & & \\
\hline
\end{tabular}


All these minerals have temperatures of melting exceeding $1450^{\circ} \mathrm{C}$; however, their blends in slag probably give sufficiently deep eutectics. It is known, in particular, that wollastonite in such blends acts as a powerful flux [14]. As a result, the slag grated into fine powder transfers into a low-viscous melt at temperatures of $700^{\circ} \mathrm{C}-800^{\circ} \mathrm{C}$, and it is aggressive against the ceramics protective crucibles and the lining of melting furnaces. When the melts were stored at $T=$ $1300^{\circ} \mathrm{C}$ for $1 \mathrm{~h}$ and quickly cooled, they transferred into brittle polycrystalline materials composed predominantly from mervinite $3 \mathrm{CaO} \cdot \mathrm{MgO} \cdot 2 \mathrm{SiO}_{2}$, perovskite $\mathrm{CaO} \cdot \mathrm{TiO}_{2}$ (slag I, II), and akermanite $2 \mathrm{CaO} \cdot \mathrm{MgO} \cdot 2 \mathrm{SiO}_{2}$ (slag III).

\subsection{The Chemical Aggressiveness of the Slag Melts}

Slags in factory practice are usually classified according to two criteria: 1 . The content of silica, which can vary from 10 (and below) up to $60 \%$, respectively, slags are considered to be basic or acidic, and a $\mathrm{pH}$ of simpler and clearer just to define the size of the percentage of $\mathrm{SiO}_{2} ; 2$. Mostly on content of the basic oxide, the slags are divided into ferrous, calcium and magnesium. The composition of the slag determines its physical and chemical properties; melting point, viscosity and character of its change with temperature, specific gravity, conductivity, surface tension etc. and chemical aggressiveness of the slag melt with respect to various refractory materials of the furnace. Under the influence of the slag melt is the destruction of the refractory material of the furnace. In Figure 1(a) and Figure 1(b) shows the appearance of the linings of cooking stoves and security of the crucible after melting slag I.

\subsection{Synthesis of Glass and Some of Their Characteristics}

In order to obtain glass based on blast-furnace slag II and III, the latter were crushed and then a dewatered silicon oxide of an analytically pure grade was added so that the glass of lots $a, b$, and $c$ for each slag contains 37,46 , and 55 mol \% of $\mathrm{SiO}_{2}$, respectively. The obtained blends were stirred in a spheric grinder for several hours. The glass was melted in a platinum crucible at a temperature

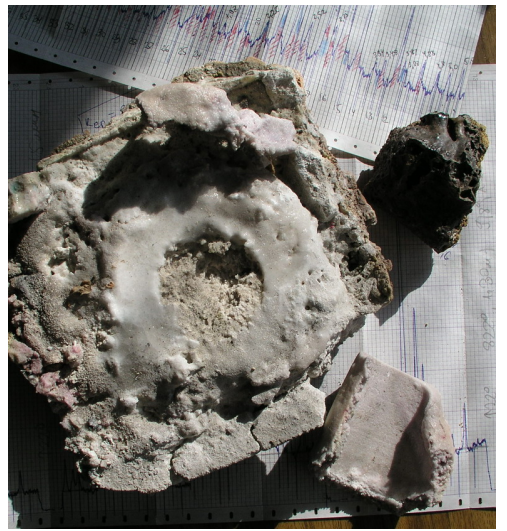

(a)

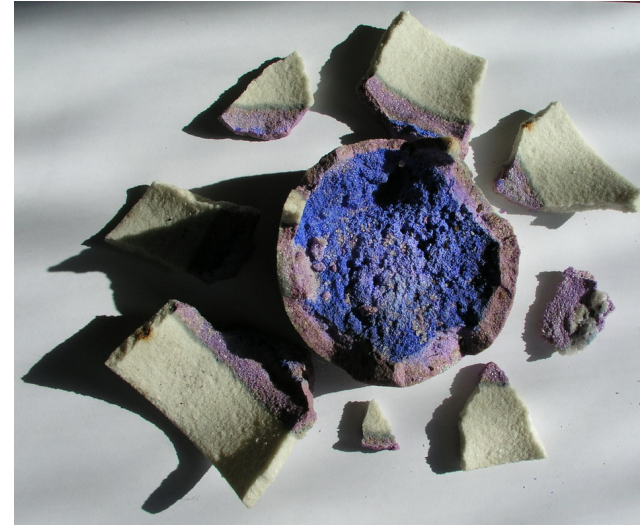

(b)

Figure 1. The appearance of the linings of cooking stoves (a) and security of the crucible (b) after melting slag I. 
of $1450^{\circ} \mathrm{C}$ for $3 \mathrm{~h}$. The glass mass was worked by melt pouring onto a massive mold with quenching between two steel plates. The calculated compositions of glass are presented in Table 3 and are denoted by II and III, corresponding to the slag numbers.

The obtained castings were transparent, X-ray-amorphous, the color of glass changed from dark brown with a reddish shade with the minimum content of $\mathrm{SiO}_{2}$ to light yellow with the maximum content of $\mathrm{SiO}_{2}$. Figure 2 shows the appearance of the original slag and glass, the synthesized on its basis.

For glass II and III, Table 4 presents densities and vitrification temperatures $T_{g}$ according to the DTA method data in comparison with temperatures $T_{13}$ corresponding to a viscosity of $10^{13} \mathrm{P}$, as well as activation energies of frictional flow in the temperature range $700^{\circ} \mathrm{C}-800^{\circ} \mathrm{C}$ for the melts of the a series glass with a low content of $\mathrm{SiO}_{2}$, which were obtained from the slope of the dependence $\ln (\eta)$ from $1 / T$.

As we can see, glass densities decrease with approximately similar growth in silica content in glass II and III. The vitrification temperatures $T_{g}$ and $T_{13}$, and, hence, the glass viscosities increase by transferring to more silica-containing glass, but to a greater degree in glass II glass than in glass III. All-in-all, glass II is less dense and more viscous than glass III, and the activation energies of frictional flow determined for the glass with the lowest silica content coincide. For the glass obtained on the base of the blast-furnace slag, high values of the viscosity criterion $\gamma=\frac{T_{g}(K)}{T_{\text {melt } 2}(K)}$ (temperature, $\left.K\right)$ are characteristic. This primarily causes the surface crystal nucleation. The temperature range for activation energy is $700^{\circ} \mathrm{C}-800^{\circ} \mathrm{C}$. The parameters of the Vogel-Fulcher-Tamman equation for glass II a: $A=-8.33 \pm 0.96, B=9352.71 \pm 892.40$, and $T_{0}=552.25 \pm 22.01$. The temperature is in $K$ and viscosity in dPa.s.

\subsection{Crystallization of Powders of Glass II}

Glass II readily crystallized from the surface, therefore, to make the results comparable, we used powders of the same dispersity in studying the crystallization:

Table 3. Chemical composition of glass based on blast-furnace slag (mol \% on synthesis).

\begin{tabular}{|c|c|c|c|c|c|c|}
\hline \multirow{3}{*}{ Oxides } & \multicolumn{3}{|c|}{ Glass II } & \multicolumn{3}{|c|}{ Glass Ш } \\
\hline & \multicolumn{6}{|c|}{ Series } \\
\hline & $a$ & $b$ & $c$ & $a$ & $b$ & $c$ \\
\hline $\mathrm{SiO}_{2}$ & 37.0 & 46.0 & 55.0 & 37.0 & 46.0 & 55.0 \\
\hline $\mathrm{Al}_{2} \mathrm{O}_{3}$ & 14.4 & 12.3 & 10.3 & 12.7 & 10.9 & 9.1 \\
\hline $\mathrm{MgO}$ & 9.9 & 8.5 & 7.1 & 7.3 & 6.2 & 5.2 \\
\hline $\mathrm{CaO}$ & 27.7 & 23.8 & 19.8 & 36.2 & 31.1 & 25.9 \\
\hline $\mathrm{TiO}_{2}$ & 7.2 & 6.1 & 5.1 & 2.1 & 1.8 & 1.5 \\
\hline Other oxides & 3.8 & 3.3 & 2.7 & 4.7 & 4.0 & 3.3 \\
\hline$K$ & 1 & 1.45 & 2.12 & 0.84 & 1.25 & 1.79 \\
\hline
\end{tabular}




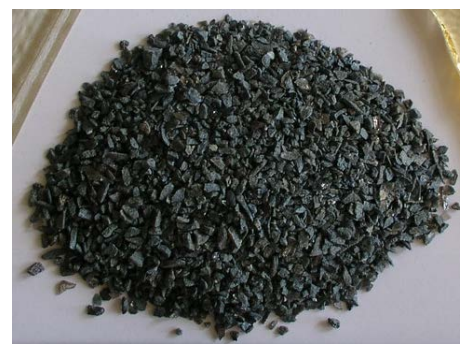

(a)

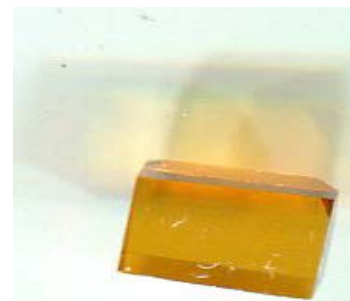

(e)

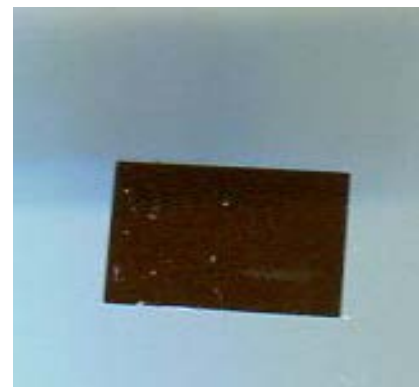

(i)

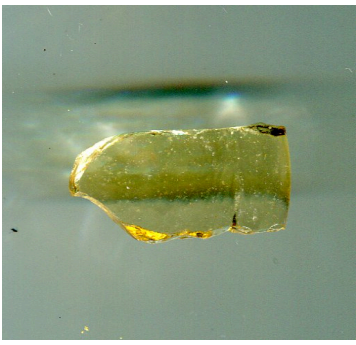

(b)

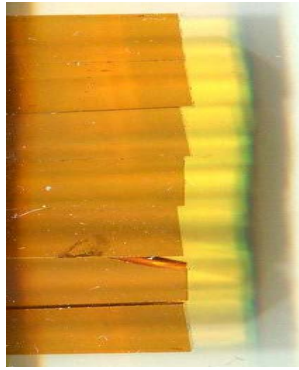

(f)

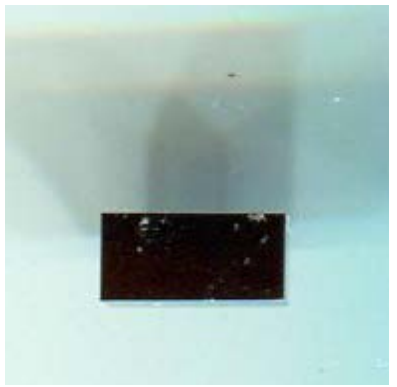

(j)

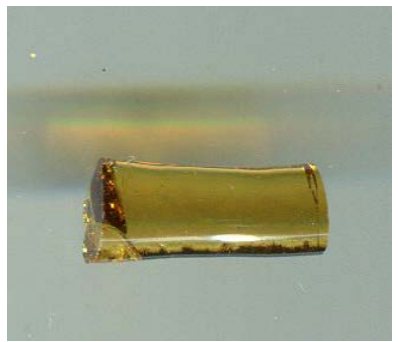

(c)

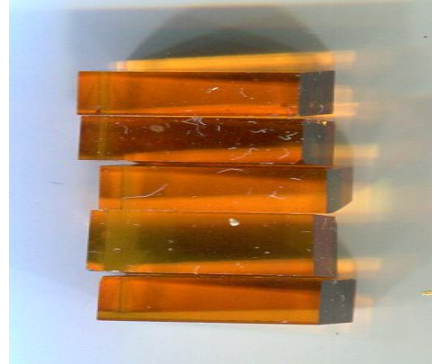

(g)

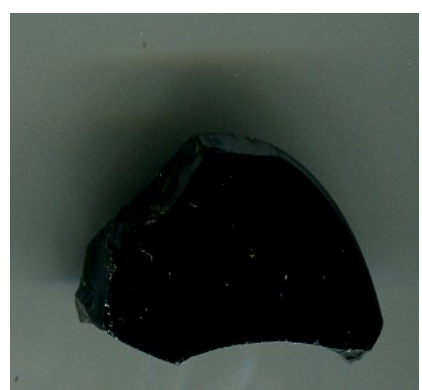

(k)

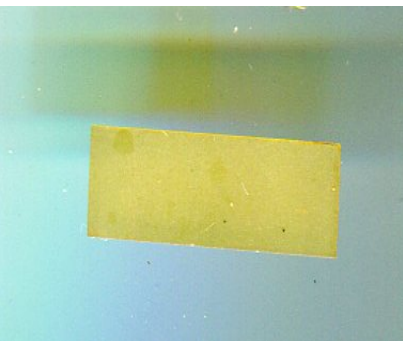

(d)

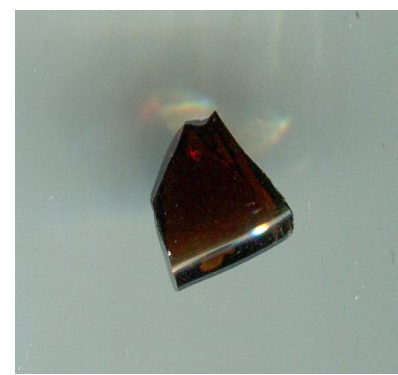

(h)

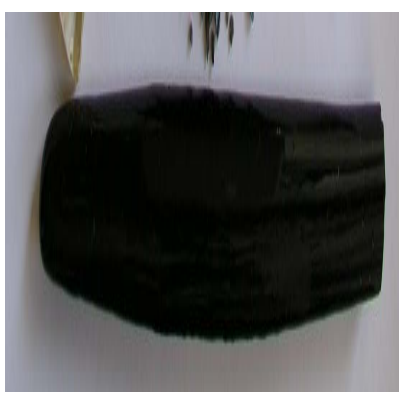

(l)

Figure 2. The appearance of the original slag (a) and glasses, the synthesized on its basis (b)-(l).

Table 4. Characteristics of glass based on slag II and III.

\begin{tabular}{ccccc}
\hline Glass & Density, $\mathrm{g} / \mathrm{cm}^{3}$ & $T_{g},{ }^{\circ} \mathrm{C}$, & $T_{13},{ }^{\circ} \mathrm{C}$ & $E_{\eta}, \mathrm{kcal} / \mathrm{mol}$ \\
\hline II, $a$ & 2.913 & 730 & 718 & 89 \\
II, $b$ & 2.786 & 735 & 740 & -- \\
II, $c$ & 2.672 & 760 & 755 & -- \\
III, $a$ & 2.920 & 718 & 709 & 713 \\
III, $b$ & 2.779 & 725 & 720 & -- \\
III, $c$ & 2.694 & 727 & -- \\
\hline
\end{tabular}

the fraction with a particle size of $0.050<d<0.065 \mathrm{~mm}$. In particular, by studying crystallization using the XPA method, glass powders of such dispersity were subjected to thermal treatment and were grated to a finely disperse state required for correct measurements using the powder technique just before the $\mathrm{X}$-ray-graphical survey.

Figure 3 shows the heating curves of powders based on the glass slag II and glass III $a$. 

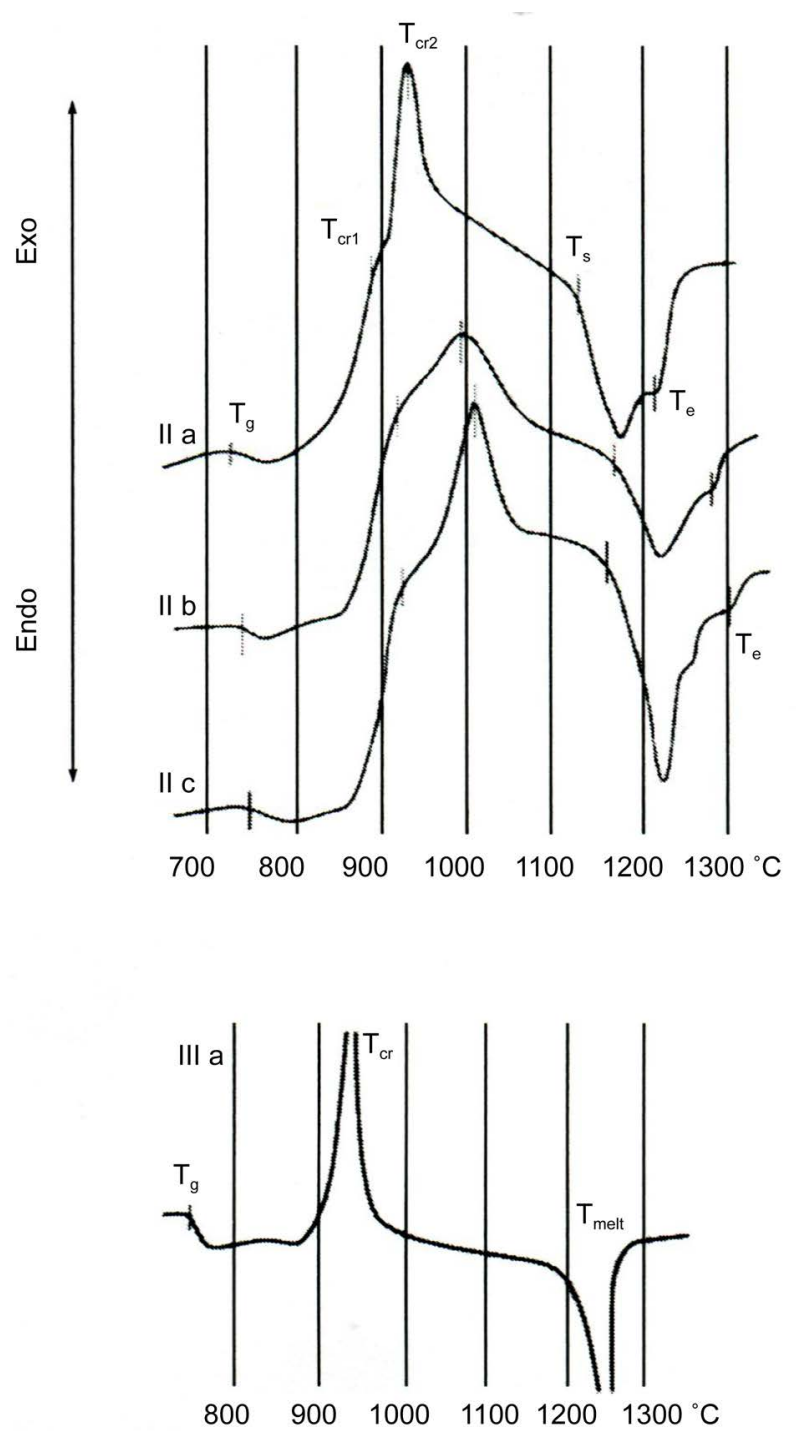

Figure 3. DTA curves of powders of glass II and glass III a. Designations are given in Table 3 .

The temperatures of vitrification $\left(T_{g}\right)$, of melting start $\left(T_{\mathrm{s}}\right)$, and its end $\left(T_{\mathrm{e}}\right)$ were determined by the crossing of the corresponding tangents. Two exothermic effects were observed on the DTA curves, which were caused by the crystallization of two different phases; they had the form of maxima and shoulders on their slopes whose temperatures corresponding to the maximal rates of crystallization are denoted as $T_{\text {cr } 1}$ and $T_{\text {cr2 }}$. The temperatures of all effects increase with an increase in the silica content, while the temperature range of melting broadens.

The XPA of powders of glass II (Figure 4) preliminarily subjected to isothermal treatment at a temperature of $850^{\circ} \mathrm{C}$, corresponding to the beginning of the first crystallization peak on the DTA curves, has shown that the crystallization starts from the simultaneous formation on the surface of the melilite glass (solid solution of gehlenite $2 \mathrm{CaO} \cdot \mathrm{Al}_{2} \mathrm{O}_{3} \cdot \mathrm{SiO}_{2}$ in akermanite $2 \mathrm{CaO} \cdot \mathrm{MgO} \cdot 2 \mathrm{SiO}_{2}$ (card-file PCPDFWIN, card 79-2423)) and diopside $\mathrm{CaO} \cdot \mathrm{MgO} \cdot 2 \mathrm{SiO}_{2}$ (PCPDFWIN, card $83-1820)$. As can be seen from Figure 4 , at temperatures above $850^{\circ} \mathrm{C}$ and 


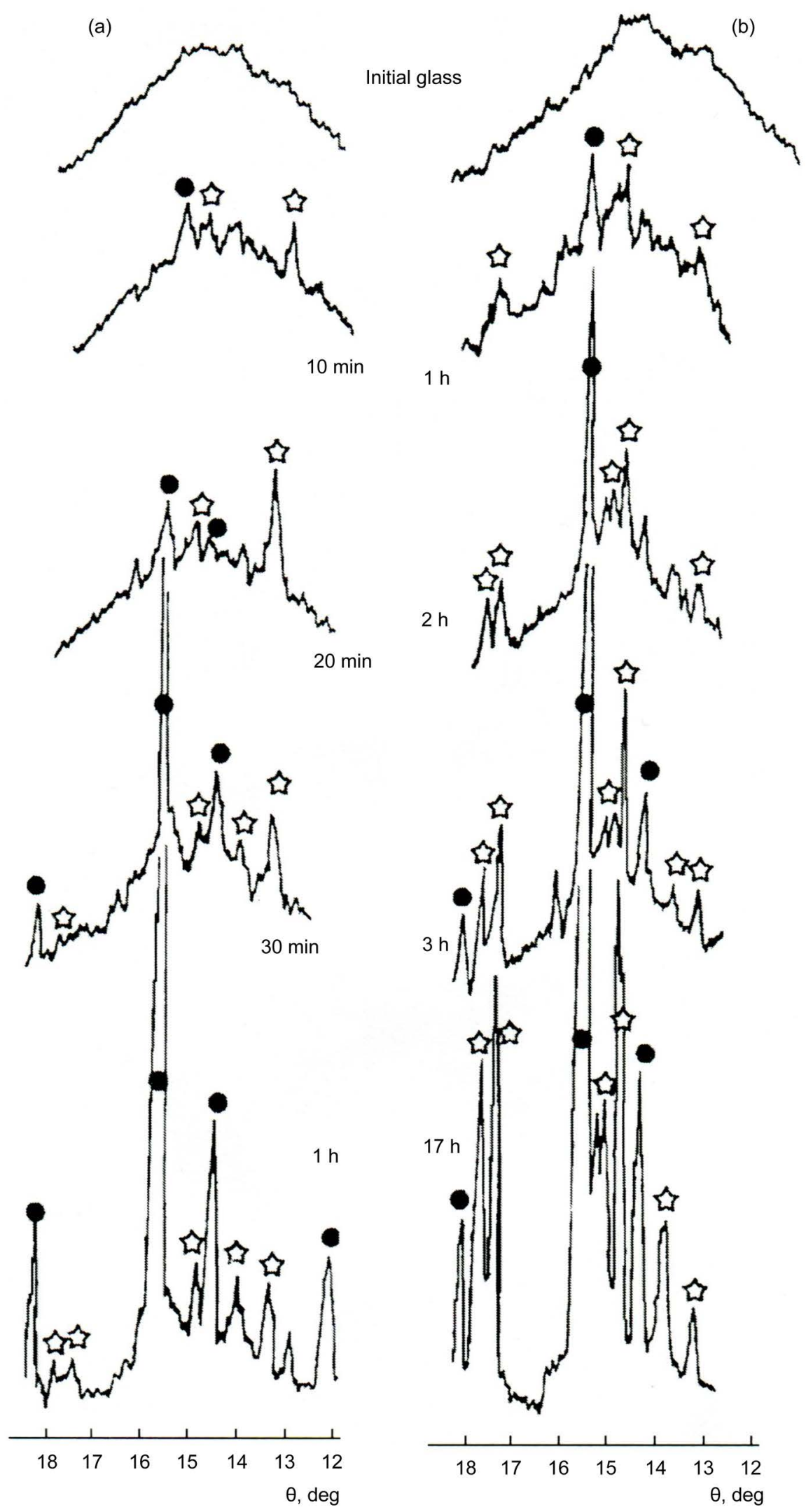

Figure 4. Crystallization of powders of glass II a (a) and II b (b) at a temperature of $850^{\circ} \mathrm{C}$ according to XPA data. Time of thermal treatment is indicated in X-ray pictures. Designations of crystalline phases: asterisks are diopside, circles are melilite. 
comparable with the temperature of $T_{\mathrm{cr} 1}$, melilite grows much quicker than diopside. The rate of diopside formation notably increases only when the temperature approaches $T_{\mathrm{cr} 2}$.

Figure 5 illustrates the difference in the rates of formation of melilite and diopside, and also the difference in the rates of crystallization of glass with different silica content.

Thus, we consider that the first crystallization peak $T_{\text {crl }}$ on the DTA curves corresponds to a predominant formation of melilite, while the second one $T_{\text {cr2 }}$ corresponds to the formation of diopside.

A comparison of the data on viscosities of slag II $\left(E_{\eta}=42 \mathrm{kcal} / \mathrm{mol}\right)$ and the data closest to it on glass composition II of slag a shows that the used additions of $\mathrm{SiO}_{2}$ more than doubled the activation energy of the melt's frictional flow. The viscosity of the slag was determined at the Nizhnetagil Combinate in the temperature interval $980.5-1062 \mathrm{~K}$. The parameters of the Vogel-Fulcher-Tamman equation for the slag II are: $A=-2.64 \pm 0.77, B=1773.62 \pm 179.92$, and $T_{0}=$ $1425.91 \pm 4.79$.

The temperatures of crystallization of glass $T_{\mathrm{cr} 1}$ and $T_{\mathrm{cr} 2}$ are also marked in Figure 6 . We note that in the crystallization of the powders of the glass of III series $a, b$ and $c$ only one clear peak was registered on the DTA curves, which was
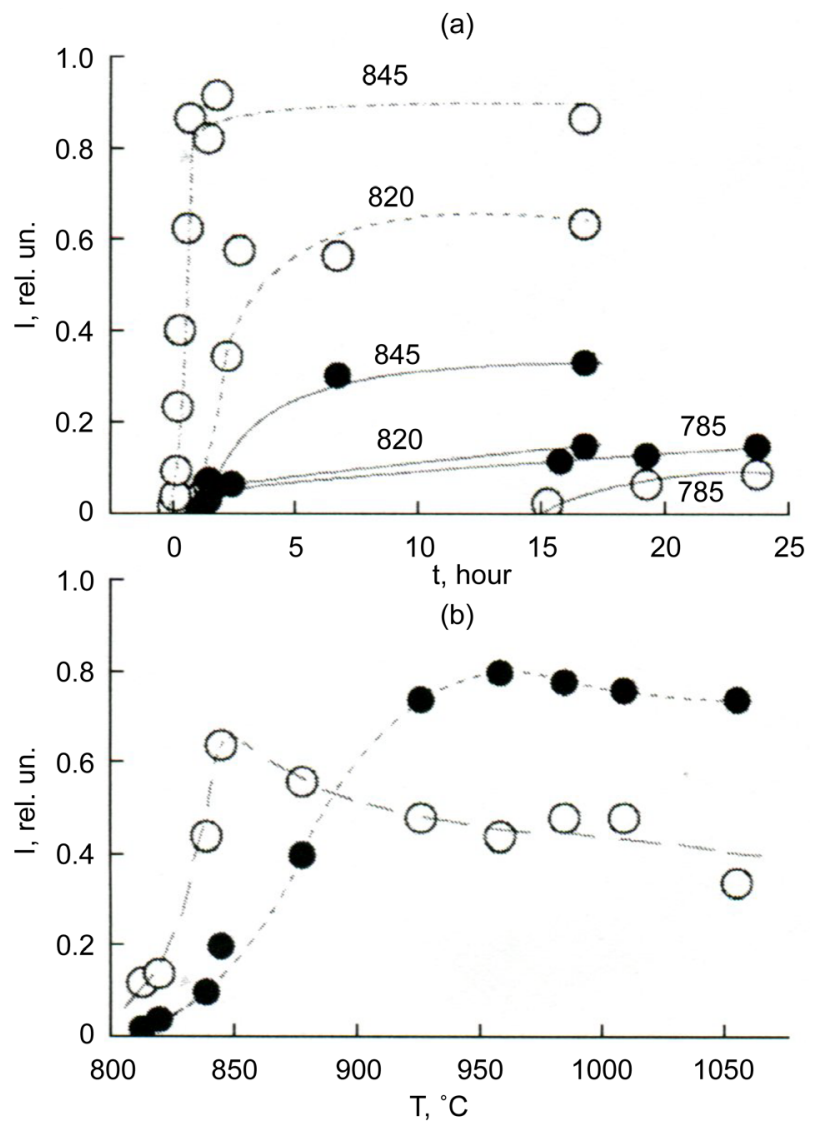

Figure 5. Dependence of the melilite and diopside formation rate on the time of thermal treatment at temperatures of $785^{\circ} \mathrm{C}, 820^{\circ} \mathrm{C}$, and $845^{\circ} \mathrm{C}$ (a) and on the temperature for thermal treatment time $10 \mathrm{~h}$ (b). Melilite-white circles, diopside-black circles. 


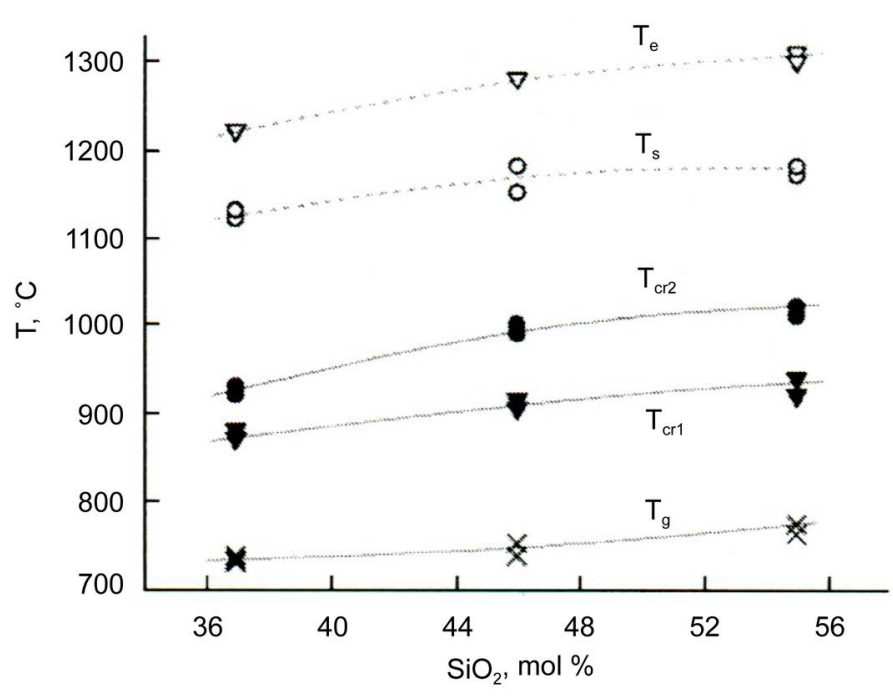

Figure 6. Temperatures of vitrification effects $\left(T_{g}\right)$, crystallization $\left(T_{\mathrm{cr} 1}\right.$ and $\left.T_{\mathrm{cr} 2}\right)$ and melting $\left(T_{\mathrm{s}}\right.$ and $T_{\mathrm{e}}$ ) on the DTA curves for powders of glass II in the dependence on silica content.

caused by the predominant crystallization of melilite and the crystallization of diopside probably, occurred slowly, which resulted in the absence of extrema on the DTA curves.

Figure 6 shows a comparison of the effects of the temperatures of vitrification $\left(T_{g}\right)$, crystallization $\left(T_{\text {cr } 1}\right.$, and $\left.T_{\text {cr } 2}\right)$, and melting $\left(T_{\mathrm{s}}\right.$ and $\left.T_{\mathrm{e}}\right)$ on the DTA curves of the powders of glass based on blast-furnace slag II depending on the content of silica in them.

As can be seen from Figure 6, the values of the temperatures mentioned increase with an increase in silica content.

\section{Chemical Differentiation in Glass III $a$}

Calcium and magnesium oxides are known to be powerful stimulators of liquation in silicate glass [15], and the boundaries of the regions of stable liquation in these systems have a silicate modulus (ratio of silica concentration to the sum of the concentrations of alkaline-earth oxides) $K=\left[\mathrm{SiO}_{2}\right] /([\mathrm{CaO}]+[\mathrm{MgO}])$ equal to 2.33 and 1.5 [15]. The crowns of metastable liquation spread to the regions with smaller silicate moduli, which, however, do not achieve unity, because, in this case, crystalline compounds, metasilicates, exist in the systems. The formation of a crystalline compound implies the miscibility of the split components and the region of its existence (in our case, $K=1$ ) is a natural boundary of nonmiscibility. As can be seen from Table 3, on the strength of the silicate modulus value, all glass of series $c$ may have a trend to splitting, which, however, is not exhibited due to the homogenizing action of $\mathrm{Al}_{2} \mathrm{O}_{3}$. The concentration of aluminum oxide in this glass $(9-10 \mathrm{~mol} \%)$ is sufficient for complete suppression of phase separation in these systems [15, p. 126]. Nevertheless, glass III $a$, which remained X-ray-amorphous possessed a microscopically inhomogeneous structure (Figure 7(a)). 

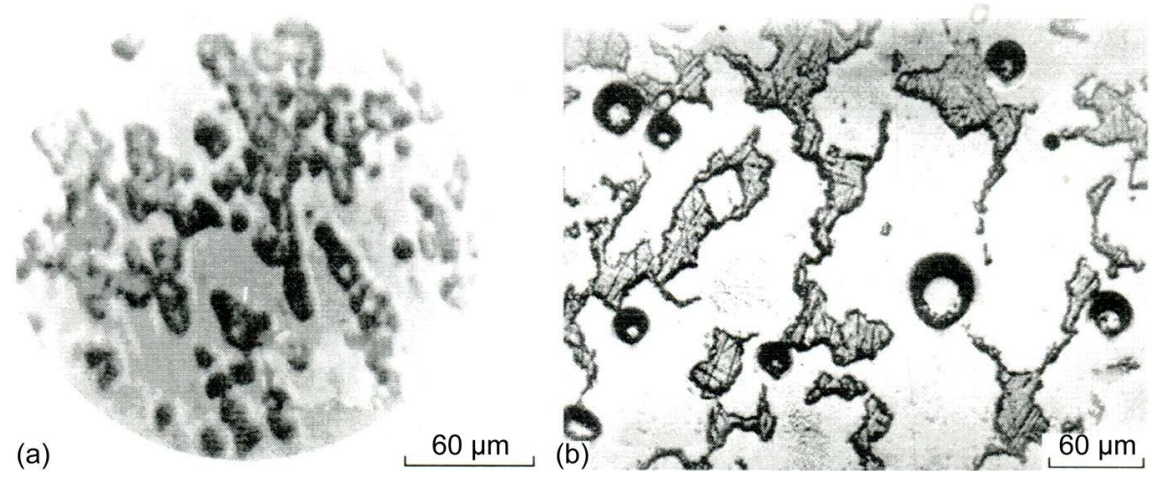

Figure 7. Microphotographs of in homogeneities in initial (a) and thermally treated glass III a at $870^{\circ} \mathrm{C}$ for $2 \mathrm{~h}(\mathrm{~b})$.

A quantitative electron-probe X-ray microanalysis (EPXMA) of quenched glass showed that dark regions in the record (regions 1) differ in composition from the light ones (regions 2) (Figure 7(a)). So, regions 1 cover $34 \%$ of glass volume and have a composition of $30.5 \mathrm{SiO}_{2} \cdot 8.4 \mathrm{Al}_{2} \mathrm{O}_{3} \cdot 11.0 \mathrm{MgO} 48.2 \mathrm{CaO} \cdot 1.9 \mathrm{TiO}_{2}$ (mol \%), i.e., contain less silica and magnesium oxide but more calcium oxide compared to regions 2, which have a composition of

$33.15 \mathrm{SiO}_{2} \cdot 7.3 \mathrm{Al}_{2} \mathrm{O}_{3} \cdot 13.5 \mathrm{MgO} \cdot 44.1 \mathrm{CaO} \cdot 2.0 \mathrm{TiO}_{2}$ ( $\mathrm{mol} \%$ ).

Thermal treatment enhances the differentiation of the regions (Figure $7(\mathrm{~b})$ ); the inhomogeneities increase in size, and from being predominantly droplet inhomogeneities are converted into labyrinth inhomogeneities (round objects, bubbles in Figure 7(b)). Both XPA and observation through the polarization microscope of thermally treated glass with the structure similar to that shown in Figure 7 (b) could not find any crystallization in them. The process of spatial differentiation of the regions by temperature growth is accompanied by a change in the chemical composition. So, according to the EPXMA data, after thermal treatment at $910^{\circ} \mathrm{C}$ for $3 \mathrm{~h}$, the relatively silicate-poor regions 1 lose part of the silica and aluminum oxide but somewhat increase the content of alkali-earth oxides. Regions 2 change their composition immaterially to $33.7 \mathrm{SiO}_{2} \cdot 5.8 \mathrm{Al}_{2} \mathrm{O}_{3} \cdot 14.3 \mathrm{MgO} \cdot 44.4 \mathrm{CaO} \cdot 1.8 \mathrm{TiO}_{2}(\mathrm{~mol} \%)$.

The relative volumes of the separated regions change with time and temperature (Figure 8); the volume of regions 1 increases while the volume of regions 2 decreases.

The volume of the regions was determined with the help of the Glagolev method [16]. At the highest studied temperature $\left(910^{\circ} \mathrm{C}\right)$, phase equilibrium is achieved after $2 \mathrm{~h}$ and the volumes of the regions stop changing with time. At this temperature, the volumes of the distinguished regions 1 and 2 are equal within the accuracy limits. We did not study the dependence of equilibrium volumes of the regions at lower temperatures, because with an increase of the exposure time the glass started to crystallize; however, Figure 8 allows us to suggest that the equilibrium volume of region 1 decreases with a decrease in temperature.

The specific behavior of glass III a described above (the presence of two types of regions in glass, their differentiation in composition, the change in the chemical 


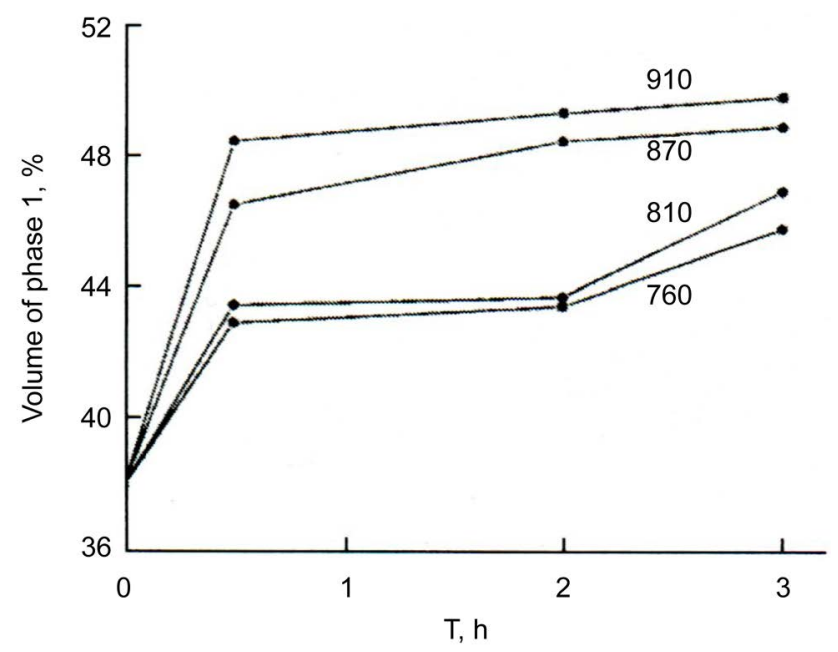

Figure 8. Volume of phase 1 in glass III a depending on the time of isothermal exposure at various temperatures. Temperatures of exposures in ${ }^{\circ} \mathrm{C}$ are denoted by the numbers on the curves.

composition with temperature, the change in the volumes of regions 1 and 2 with time) is a characteristic feature of liquation; however, the values of the observed inhomogeneities' orders of magnitude exceed the typical ones for nonmiscibility in silicate glass. Glass III $a$ is the only studied glass that has a silicate modulus that is smaller than unity; i.e., it is in the so-called inverted region of compositions. It is possible that in addition to the known region of liquation located in the high-silica part of the system and limited by the composition of metasilicate, there is one more region of liquation with a content of $\mathrm{SiO}_{2}$ of about 30 - $40 \mathrm{~mol} \%$.

Splitting in slag melts was also mentioned earlier. So, according to [17], the chemical differentiation of glass obtained on the basis of slag precedes crystallization. In this case, splitting takes place in the only type of glass studied in this work, glass III $a$, which possesses the silicate modulus $K=\left[\mathrm{SiO}_{2}\right] /([\mathrm{CaO}]+$ $[\mathrm{MgO}])=0.84<1($ Table 3$)$, i.e., in a glass located in the inverted region of compositions.

Thus, the splitting in glass III $a$ is not associated with the well known regions of stable liquation but probably represents a particular closed region inside the multicomponent diagram. The existence of nonmiscibility regions not associated with any of the formed subsystems is known from the literature [18].

As the electron-probe microanalysis showed, microscopic inhomogeneities developed as the temperature and treatment time increased. In the process of thermal treatment, the difference in the phase compositions of regions 1 and 2 increases: region 1 is depleted with silica and enhanced with $\mathrm{CaO}$, while the composition of region 2 changes in the opposite direction, and the content of other oxides in these regions is approximately equal.

\section{Kinetics of Volume Crystal Nucleation in Glass III $a$}

Among the nine types of glass synthesized in our work, only one (III a) pos- 
sessed volume crystallization. Melilite crystals in this glass nucleated both at the surface with the subsequent growth inside the sample and in the volume, in the latter case, the melilite nucleation took place in the crystals of perovskite formed in the glass volume. At $740^{\circ} \mathrm{C}$, the spinel phase of perovskite $\left(\mathrm{CaO} \cdot \mathrm{TiO}_{2}\right)$ appeared in this glass volume formed due to the interaction of titanium oxide and calcium oxide, which then served as a catalyst for the volume nucleation of melilite crystals in the temperature range $840^{\circ} \mathrm{C}-1100^{\circ} \mathrm{C}$. Further, we will speak of volume nucleation of perovskite and melilite crystals.

To describe the kinetics of homogeneous and heterogeneous nucleation of crystals in glass, we used the following main parameters: steady-state rate of nucleation $I_{\mathrm{st}}$, the time of non-steady-state nucleation $\tau$ (its measurement in the experiment is the time of the induction period $t_{\text {ind }}$ ), the rate of crystal growth $U$, and the temperature dependences of the values mentioned. The value of $I_{\mathrm{st}}$ was determined from the experimentally found dependences of the number of nucleating crystals in a unit of volume $n(t)$ as the slope ratio of the steady-state part of these dependences on the glass exposure time $t$ at each given temperature $T$; $t_{\text {ind }}$ for each temperature $T$ was found by crossing the linear part of the expansion of the dependences $n(t)$ with the time axis $t$. The values of $n(t)$ were determined as follows. The samples of glass measuring $\sim 130 \mathrm{~mm}^{3}$ were subjected to nucleation thermal treatments in a preset temperature range and quickly cooled in air to room temperature. To accelerate finding the temperature interval for crystal nucleation, we used a DTA curve because the maximum crystal nucleation rate as a rule is located near the vitrification temperature on the DTA curve and at a temperature corresponding to a viscosity of $10^{13} \mathrm{P}$.

\subsection{Kinetics of Volume Crystal Nucleation of Perovskite in Glass III $a$}

For the nucleation of catalyzing phase crystals (perovskite), samples of the initial glass were exposed in the temperature range $740^{\circ} \mathrm{C}-850^{\circ} \mathrm{C}$ (the region between $T_{g}$ and the start of crystallization on the DTA curve). The optimal temperature value for growing (visualization) nucleated crystals up to sizes observable by an optical microscope is $930^{\circ} \mathrm{C}$ (the temperature corresponding to the middle of the ascending branch of the exothermal peak on the DTA curve). When the glass is heated in the interval of $740^{\circ} \mathrm{C}-850^{\circ} \mathrm{C}$ for $24 \mathrm{~h}$, two phases appear successively. Perovskite $\mathrm{CaO} \cdot \mathrm{TiO}_{2}$ is precipitated first (Figure $9(\mathrm{a})$ ) and the second phase is melilite, which crystallizes in the form of rosettes on the perovskite crystals (Figure 9(b)).

Electron microscopy was carried out on an EM-125 transmission electron microscope using the method of carbon replicas at an accelerating voltage of $75 \mathrm{kV}$.

The nature of crystalline phases was determined by XPA. After lasting lowtemperature exposures $\left(740^{\circ} \mathrm{C}\right.$, for $24 \mathrm{~h}$ and more) diffraction maxima appeared on the X-ray pictures, which can be attributed to $\mathrm{CaO} \cdot \mathrm{TiO}_{2}$ (card 83-231 in PCPDFWIN). Exposures at the development temperatures $\left(930^{\circ} \mathrm{C}, 30 \mathrm{~min}\right)$ resulted in melilite crystallization (PCPDF-WIN, card 79-2423). The number of 

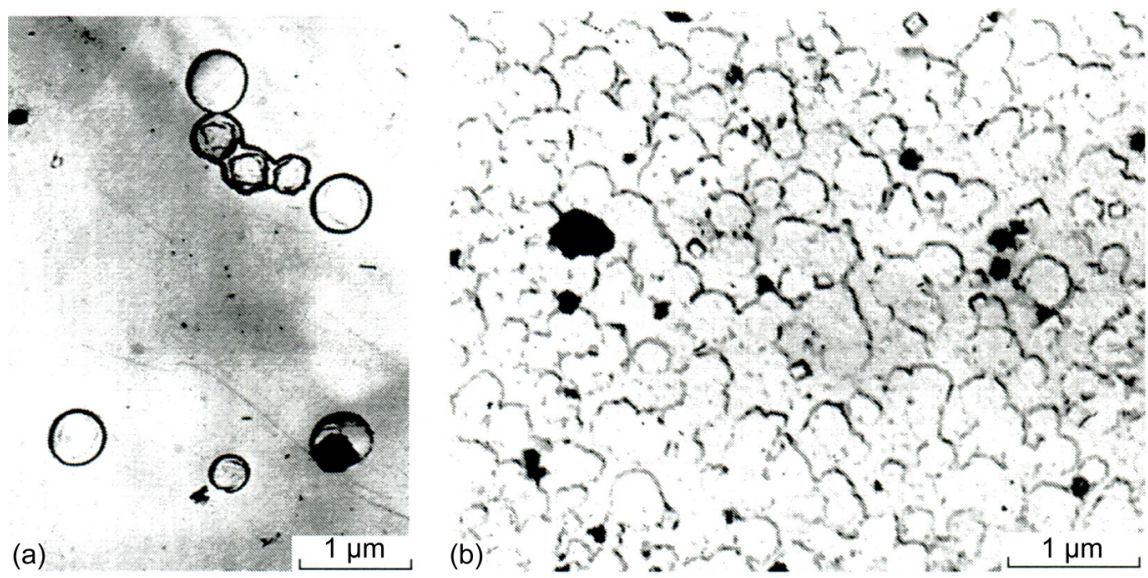

(c)

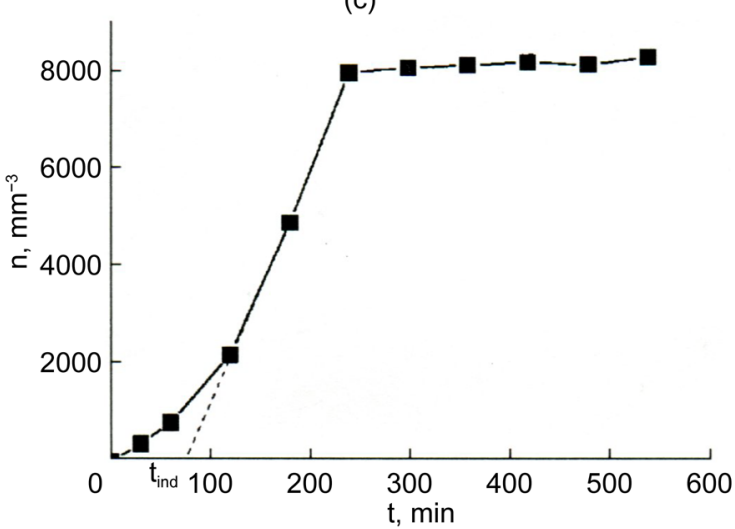

Figure 9. Electron-microscopic pictures of crystals of perovskite (a) and melilite (b) in glass III a and dependence of the number of perovskite crystals $\mathrm{n}$ on time of low-temperature thermal treatment at $740^{\circ} \mathrm{C}$; time of development at $930^{\circ} \mathrm{C}$ is $5 \mathrm{~min}$ (c). Thermal history: $740^{\circ} \mathrm{C}, 24 \mathrm{~h}$ for perovskite (a) and $740^{\circ} \mathrm{C}, 24 \mathrm{~h}+930^{\circ} \mathrm{C}, 30 \mathrm{~min}+980^{\circ} \mathrm{C}, 30 \mathrm{~min}$ for melilite (b).

rectangular crystals is very small. They cannot be detected by the X-ray graphical method as an individual phase. It is possible that these are those crystals of perovskite at which crystals of melilite are not grown.

Then, the samples were subjected to repeated thermal treatment at a development temperature of $930^{\circ} \mathrm{C}$ for $5 \mathrm{~min}$.

After the thermal treatments the surface layer was ground off from the samples and the obtained surface was polished. To increase the sharpness of the interfaces between the crystals and the glass, the surface of the sample was etched in a $0.01 \mathrm{M}$ solution of fluoric acid for $10 \mathrm{~s}$. The number of sections of crystals $N_{S}$ and their size on the section surface unit of area $S$ were determined with the help of a Neophot optical microscope in reflected light. The number of crystals in a unit of volume and the number of crystal sections in a unit of area are connected by the relation $n=N_{S} /\left(S D_{\text {av }}\right)$, where $D_{\text {av }}=\left(D_{1}+D_{2}\right) / 2 .\left(D_{1}\right.$ and $D_{2}$ are the maximal and minimal sizes of crystal traces on the section). We note that in order to count the crystals, we used samples in which the crystals do not fuse with each other. Figure 9 (b) corresponds to the complete over crystallization of a sample. 
Figure 9 (c) shows dependence $n(t)$ for the nucleation of perovskite crystals at a temperature of $760^{\circ} \mathrm{C}$. Similar dependences were also obtained for other temperatures. It turned out that the systematic dependences of the change in the saturation level with temperature are not observed.

The dependences $n(t)$ first went through a region where an increase in the number of crystals was nonlinear and then, when a certain moment of time was achieved, they became linear. The steady-state rate of crystal nucleation $I_{\mathrm{st}}=$ $\mathrm{d} n / \mathrm{d} t$ was determined for this region (Table 5).

Figure 9(c) reflects a feature of the nucleation of perovskite crystals. It consists in the fact that after certain duration of thermal treatment the number of developed perovskite crystals does not change with time. Because the nucleation proceeds in the glass sharply differs in composition from that of perovskite, the rate of nucleation of crystals strongly depends on time. It is reduced in the process of perovskite crystallization due to the reduction of the amount of titanium oxide in glass. The dependence of crystallization parameters on time is a peculiarity of the case under consideration in comparison with the crystallization of glass of stoichiometric composition.

By using the curves of the type presented in Figure 9(c) for other temperatures, we determined values $I(T)$ and built the temperature dependence of the nucleation rate of perovskite crystals: maximal value of the rate $I_{m_{\text {perossite }}}=2 \times$ $10^{3} \mathrm{~mm}^{-3} \cdot \mathrm{min}^{-1}$ at $T_{m}=740^{\circ} \mathrm{C}$.

The crystal growth rate was determined for every development temperature from the relation $U=\mathrm{d} R / \mathrm{d} t$, where $t$ is the time of glass exposure at the development temperature. By determining the rates of nucleation and growth of

Table 5. Values of $I_{\mathrm{st}}(T)$ and $U(T)$ for crystals of perovskite and melilite in glass III $a$.

\begin{tabular}{|c|c|c|c|c|}
\hline \multirow{2}{*}{$\mathrm{T},{ }^{\circ} \mathrm{C}$} & \multicolumn{2}{|c|}{ Perovskite } & \multicolumn{2}{|c|}{ Melilite } \\
\hline & $I_{s t}(T), \mathrm{mm}^{-3} \cdot \mathrm{min}^{-1}$ & $U, \mathrm{~mm} / \mathrm{min}$ & $I_{s t}(T), \mathrm{mm}^{-3} \cdot \mathrm{min}^{-1}$ & $U, \mathrm{~mm} / \mathrm{min}$ \\
\hline 640 & 1220 & - & - & - \\
\hline 700 & 1630 & - & - & - \\
\hline 740 & 2000 & - & - & - \\
\hline 760 & 1900 & $1.1 \times 10^{-3}$ & - & - \\
\hline 780 & 1700 & - & - & - \\
\hline 800 & 1580 & $1.45 \times 10^{-3}$ & - & - \\
\hline 820 & 1420 & - & - & - \\
\hline 840 & 1250 & - & 0.001 & 0.1 \\
\hline 860 & 1120 & $2.27 \times 10^{-3}$ & 0.015 & 1.32 \\
\hline 885 & 960 & - & - & - \\
\hline 900 & 820 & $0.8 \times 10^{-3}$ & - & - \\
\hline 915 & - & $0.7 \times 10^{-3}$ & 0.33 & 4.5 \\
\hline 950 & - & - & 0.133 & 11.1 \\
\hline 995 & - & - & 0.001 & 5.5 \\
\hline
\end{tabular}


crystals, we took the average radius of the maximal crystal trace on the section as $R$. The dependences of maximal spherulites radii $R_{\max }$ on the development time had a linear character, and this circumstance allowed us to determine the steady-state rate of growth at a given temperature using its slope.

As can be seen from Figure 10, thermal treatments to $640^{\circ} \mathrm{C}$ did not substantially affect the kinetics of the nucleation of the catalyzing phase-perovskite. Starting with $640^{\circ} \mathrm{C}$, the influence of thermal treatments became noticeable; it consisted in the appearance of a certain number of perovskite crystals, which were registered both by the X-ray-graphical method and by the optical microscope.

\subsection{Kinetics of Volume Crystal Nucleation of Catalyzed Phase-Melilite in Glass III $a$}

Melilite starts nucleating from $870^{\circ} \mathrm{C}$.

To obtain the data on the kinetics of melilite nucleation on perovskite crystals, the initial glass was first exposed at the maximum temperature of the perovskite crystal nucleation rate $\left(740^{\circ} \mathrm{C}\right)$, in order to release the whole perovskite in the form of crystals on which melilite nucleates. In this case, melilite still did not appear in appreciable amounts. Then, the samples of glass prepared in such a way were subjected to thermal treatments at higher temperatures (Figure 10). The dependences $n(t)$ for melilite crystals were built in a similar way. The number of developed melilite crystals does not change with time after a certain time of treatment as in the case with curves, this can be associated both with the change in the glass composition in the process of melilite crystallization and with the gradual depletion of melilite nucleation centers, crystals of perovskite. The number of perovskite crystals not actuated as catalysts can be written in the form

$$
\begin{aligned}
& n_{\text {perovskite }}(t)=n_{\text {perovskite }_{0}} \exp (-\alpha t), \\
& d n_{\text {perovskite }}=-n_{\text {perovskite }} \alpha d t,
\end{aligned}
$$

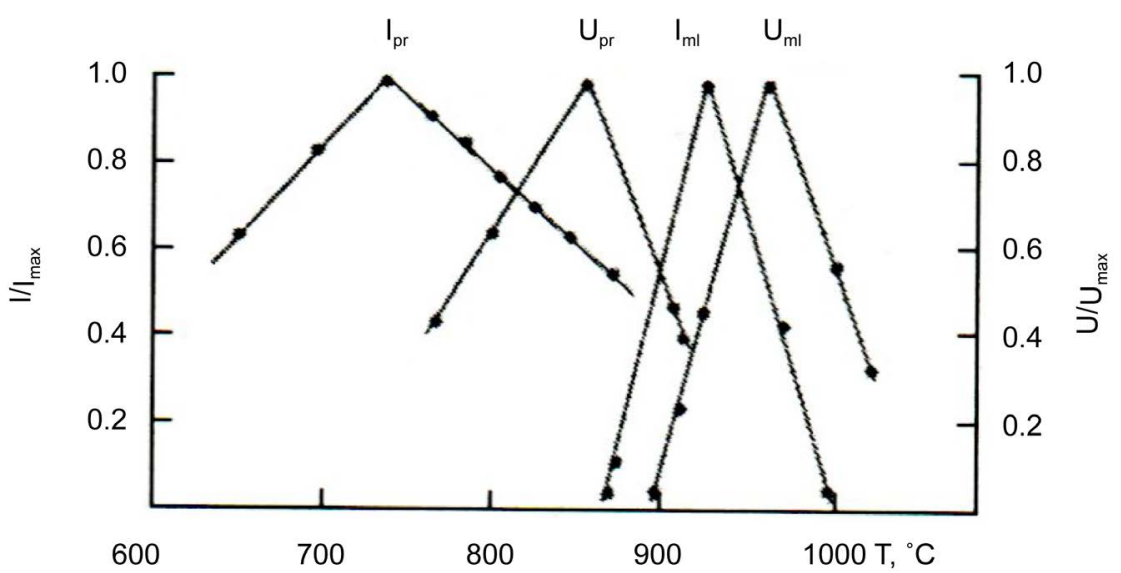

Figure 10. Temperature dependences of reduced values of steady-state rates of perovskite nucleation $I_{p r}$ and melilite nucleation $I_{m l}$ and growth of perovskite $U_{p r}$ and melilite $U_{m l}$ for glass III a. 
where $\alpha$ is the probability of nucleation of a spherulites of melilite on perovskite crystals in a unit of time. The value $\alpha$ can be referred to as the catalytic activity of perovskite crystals with regard to melilite. It depends on the relationship between the parameters of the catalyst crystalline cell and the nucleating crystal of the basic phase of melilite there. Then, nucleation rate of spherulites of melilite is equal to $I=-\mathrm{d} n_{\text {perovskit }} / \mathrm{d} t=\alpha n_{\text {perovskit }}$. This will lead to a reduction of $I(t)$ with time as $n_{\text {perovskite }}$ in (1). The maximum $I$ for melilite (catalyzed phase) is located at temperature $T_{m}=915^{\circ} \mathrm{C}$, which is $170^{\circ} \mathrm{C}$ higher than for perovskite. The rate of melilite catalyzed nucleation is approximately proportional to the general number of perovskite particles and the average area of a single particle surface and amounts at the maximum to the value $0.33 \mathrm{~mm}^{-3} \cdot \mathrm{min}^{-1}$.

\subsection{Results and Discussion of Nucleation in Glasses Based on Blast Furnace Slag}

Glass based on the blast-furnace slag of Chelyabinsk Metallurgical Combinate is obtained. It is established that for glass obtained based on the blast-furnace slag; the high values of the viscosity criterion $\gamma=\frac{T_{g}}{T_{\text {melt } 2}}$ are typical. This mainly leads to the surface nucleation of the crystals. Only one of the nine selected compositions with the ratio of the main components $\mathrm{TiO}_{2}: \mathrm{CaO}: \mathrm{MgO}: \mathrm{Al}_{2} \mathrm{O}_{3}: \mathrm{SiO}_{2}$ $=1: 7 \cdot 2: 1 \cdot 8: 2 \cdot 6: 7.4$ was prone to volume nucleation. At $600^{\circ} \mathrm{C}$, in the bulk of the glass, the perovskite spinel phase appeared, which then served as a catalyst for the bulk nucleation of the crystals of melilite in the temperature range of $840^{\circ} \mathrm{C}$ $1100^{\circ} \mathrm{C}$. Melilite crystals were nucleated both on the glass surface and then grew into the sample and in the volume.

The crystals of diopside $\left(\mathrm{CaO} \cdot \mathrm{MgO} \cdot 2 \mathrm{SiO}_{2}\right)$ were nucleated only on the surface. It is established that for a glass exhibiting the volume nucleation of crystals the mechanism of crystallization is associated with three main processes. The first is the process of chemical differentiation of the glass, leading to the formation of an inhomogeneous glass structure. The second process is the homogeneous formation of centers of crystallization. It consists in the formation of the spinel phase of perovskite, which is a catalyst for the formation of the basic crystalline phase, melilite. The third process consists in the formation of the basic catalyzed crystalline phase of melilite.

A separate investigation into temperature dependences of the rates of nucleation and growth of the catalyzing phase (perovskite) and the basic phase (melilite) in pyroxenic glass is carried out. The volume parameters of the nucleation of the catalyzing and catalyzed-phase crystals are determined: the temperature dependences of the steady-state rate of nucleation and growth of crystals. The maximal values of the crystal nucleation rates for the catalyzing and catalyzed phases are found.

Using the example of the crystallization of perovskite and melilite in glass III $a$, for the first time, we built the complete Tamman curves for the glass of complicated industrial compositions and the ways are shown that allow us to shorten 
the time for searching for the chemical composition and temperature-time conditions of crystallization for the development of an expedient technology for producing glass-crystalline materials.

\section{Bulk Crystal Nucleation Catalyzed by $\mathrm{Cr}_{2} \mathrm{O}_{3}$ in Glasses Based on Blast Furnace Slag}

Analysis of the papers, devoted to the study of the crystallization in compositionally similar crystals [19]-[31] shows that to promote the nucleation of the crystals in the volume, most researchers prefer chromium sesquioxide as catalysts. In connection with this, we used $\mathrm{Cr}_{2} \mathrm{O}_{3}$ to stimulate the volume nucleation in the glass and studied the nucleation kinetics of the catalytic phase-of the magnesiochromite on which the nucleation and growth of the catalyzed phase then took place-of the diopside. Investigation of the kinetics of nucleation and crystal growth is the theoretical basis of the main stages of the production of glass ceramics based on furnace slags.

\subsection{Synthesis and Characterization of Glass of the Original Composition with $\mathrm{Cr}_{2} \mathrm{O}_{3}$ Content}

In order to obtain glass based on furnace slags with $\mathrm{Cr}_{2} \mathrm{O}_{3}$ content, they were pulverized, then the anhydrous silica a drum. The glass was cooked in a platinum crucible at $1450^{\circ} \mathrm{C}$ for $3 \mathrm{~h}$. The glass mass was produced in an array metal mold with further pressing by a metal anvil. These castings were transparent and $\mathrm{X}$-ray amorphous. Figure 11 presents the appearance of glass based on furnace slags (slag in the center).

The experiment showed that the glass color has changed from dark brown with a reddish tinge (for the minimum content of $\mathrm{SiO}_{2}$ ) to light yellow (with the

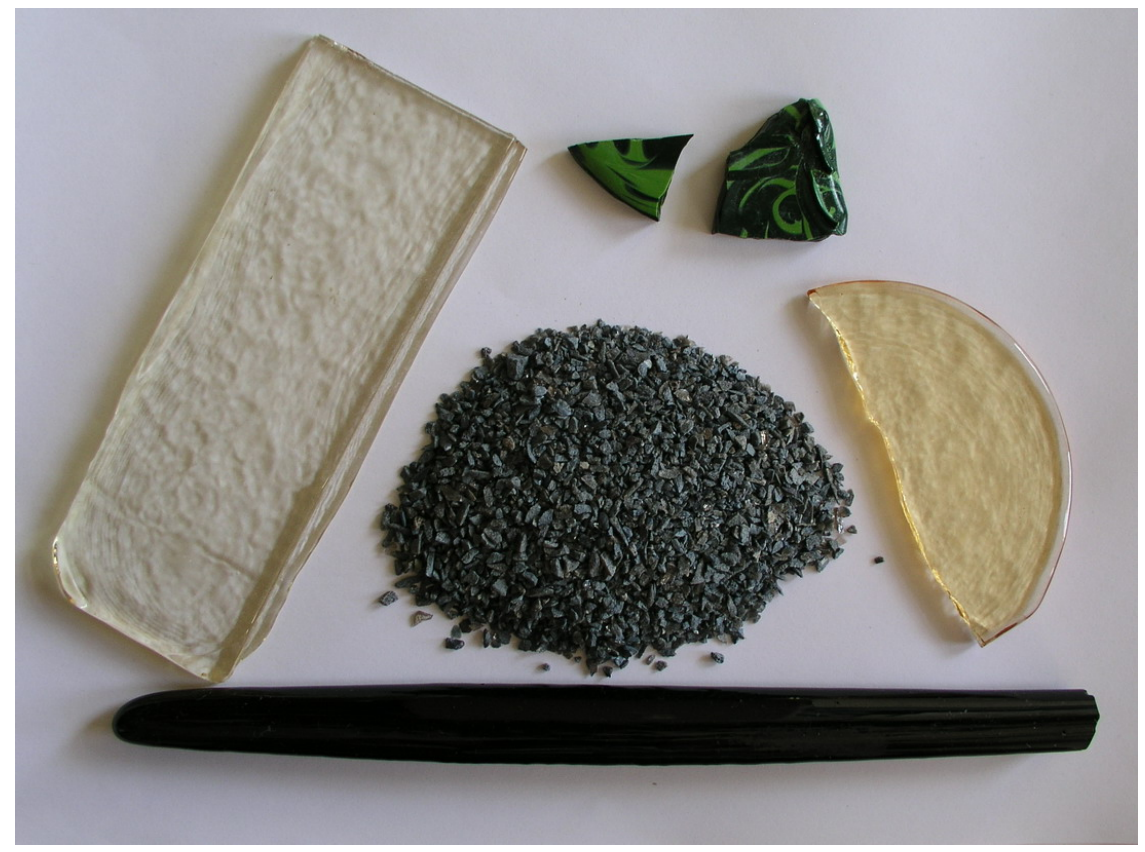

Figure 11. Appearance of glass based on furnace slags (slag is in the center). 
maximum content of the $\mathrm{SiO}_{2}$ ). The glass with excess $\mathrm{Cr}_{2} \mathrm{O}_{3}$ content has a characteristic malachite color. Surface crystallization was observed in all types of glass. It started in the temperature range close to the glass transition temperature $T_{\mathrm{g}}$ for the studied glass $\left(730^{\circ} \mathrm{C}-770^{\circ} \mathrm{C}\right)$.

With increasing temperature under the action of surface tension forces, the glass melted slightly. In order to stimulate volume nucleation of the crystals, chromium oxide was used as the catalyst in amounts varying from 1 to $10 \mathrm{wt} \%$ (over 100). The experiments have been carried out on glass Ia. Figure 12 shows the appearance of chromium-containing slag glass. The best result was obtained for glass with 2 wt $\%$ of $\mathrm{Cr}_{2} \mathrm{O}_{3}$ (over 100\%) (Figure 12(a)). The glass was green and transparent. The increase in the content of $\mathrm{Cr}_{2} \mathrm{O}_{3}$ led to the appearance of the characteristic pattern of the malachite (Figure 12(b)).

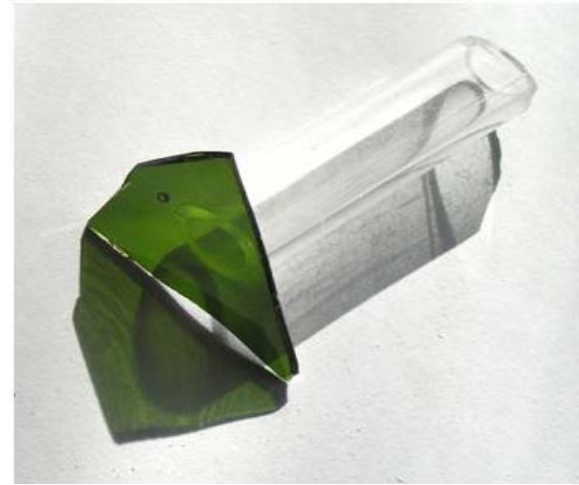

(a)

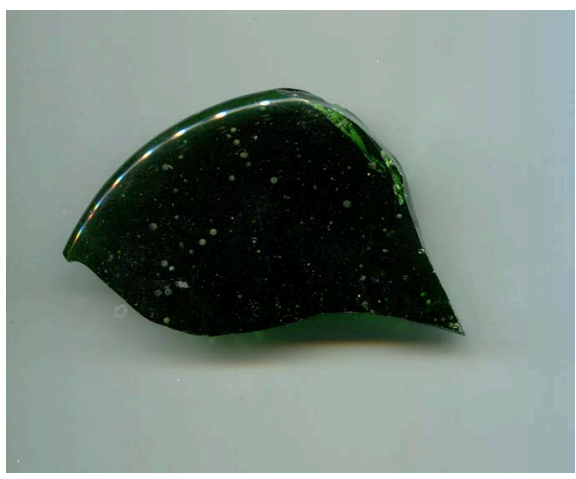

(c)

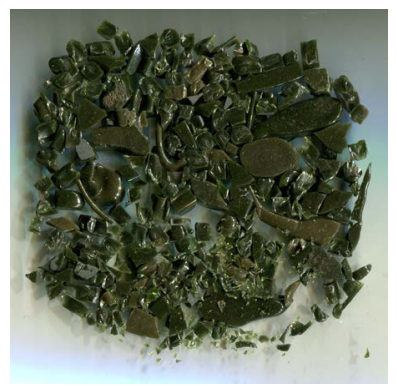

(e)

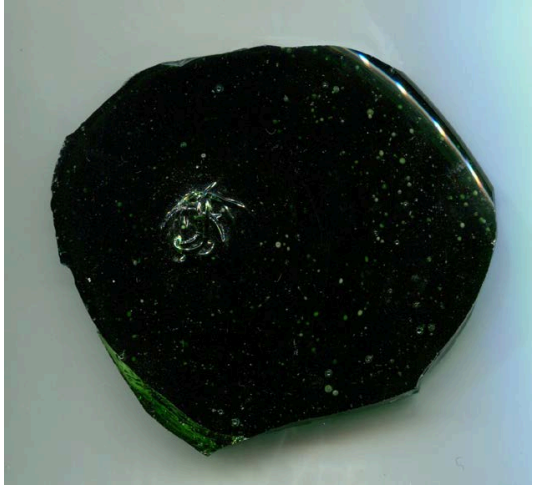

(b)

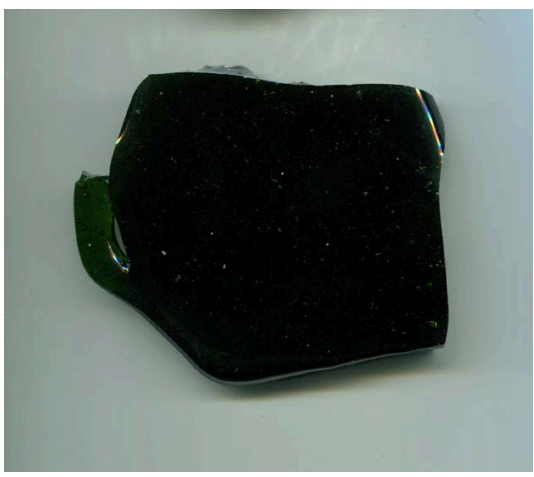

(d)

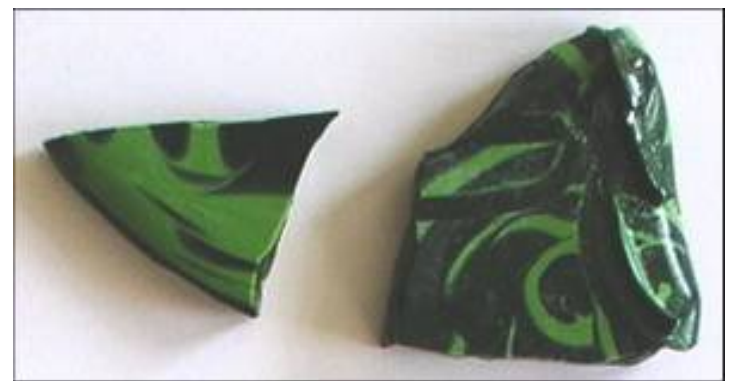

(f)

Figure 12. Appearance of chromium containing slag glass: 2 wt $\%$ of $\mathrm{Cr}_{2} \mathrm{O}_{3}$ (a)-(e), 5 wt $\%$ of $\mathrm{Cr}_{2} \mathrm{O}_{3}$ (f). 
This glass is uniform in composition and, along with the surface nucleation of the crystals, appears volume. A smaller amount of $\mathrm{Cr}_{2} \mathrm{O}_{3}$ had no significant influence on the character of the nucleation and increased content led to the excess $\mathrm{Cr}_{2} \mathrm{O}_{3}$ not being digested by the glass. The excess $\mathrm{Cr}_{2} \mathrm{O}_{3}$ led to the nucleation becoming uniform in composition with a characteristic malachite pattern (Figure 12(b)). According to XRPA, the magnesiochromite phase first precipitated in the glass $\left(\mathrm{MgO} \cdot \mathrm{Cr}_{2} \mathrm{O}_{3}, \mathrm{PCPDFWIN}\right.$ no. 10-0351), and then the diopside (CaO-MgO-2SiO 2 , PCPDFWIN no. 75-1577). As in the case of the study of the influence of perovskite on the nucleation of melilite crystals in the slag glass, the kinetic and temperature dependences were obtained first of the nucleation of the catalyzing phase-of magnesiochromite and then of the catalyzed phase-of diopside.

\subsection{Kinetics of the Volume Nucleation of Crystals in Glass I a with an Admixture of $\mathrm{Cr}_{2} \mathrm{O}_{3}$}

The diopside crystals in this glass were nucleated both on the surface followed by germination into the sample and in the volume. In the latter case, the nucleation of diopside occurred on the magnesiochromite crystals formed in the glass bulk. At $720^{\circ} \mathrm{C}$, the spinel phase of magnesiochromite $\mathrm{MgO} \cdot \mathrm{Cr}_{2} \mathrm{O}_{3}$ appeared in the glass bulk, which then served as a catalyst for the volume nucleation of the diopside crystals in the temperature range of $800^{\circ} \mathrm{C}-870^{\circ} \mathrm{C}$.

For the nucleation of the crystals of the catalyzing phase-magnesiochromite - samples of the original glass were kept in the temperature range of $720^{\circ} \mathrm{C}$ $850^{\circ} \mathrm{C}$ (the area between $T_{\mathrm{g}}$ and the beginning of the crystallization on the DTA curve). The development temperature of the nucleating crystals to a size visible in an optical microscope is $880^{\circ} \mathrm{C}$, according to the DTA curve.

Upon heating the glass in this range of $720^{\circ} \mathrm{C}-850^{\circ} \mathrm{C}$ for $24 \mathrm{~h}$, two phases appear sequentially (Figure 13).

Magnesiochromite is precipitated first $\left(740^{\circ} \mathrm{C}, 4 \mathrm{~h}\right)$ and then at $\left(750^{\circ} \mathrm{C}, 4 \mathrm{~h}+\right.$ $880^{\circ} \mathrm{C} 20 \mathrm{~min}$ ) diopside, which crystallizes in the form of sockets on the magnesiochromite crystals, is precipitated.

\subsubsection{Characteristics of the Volume Nucleation of the Catalyzing Phase of Magnesiochromite}

The values of $n(t)$ were determined as follows. The samples of $\sim 130 \mathrm{~mm}^{3}$ of glass were subjected to nucleation thermal treatments in a predetermined temperature range and rapidly quenched in air to room temperature. Then the samples were subjected to reheating treatment at a developing temperature of $930^{\circ} \mathrm{C}$ for $5 \mathrm{~min}$. After heat treatment, the surface layer was ground off the samples and the obtained surface was polished. To increase the contrast of the boundaries between the crystals and the glass, the surface of the sample was etched in $0.01 \mathrm{~N}$ hydrofluoric acid solution for 10 seconds. The number of sections of $N_{S}$ crystals and their size on a unit area of the surface section $S$ were determined using a Neophot optical microscope in reflected light. The number of crystals in unit volume and the number of sections of crystals on a unit area are related by the ratio 


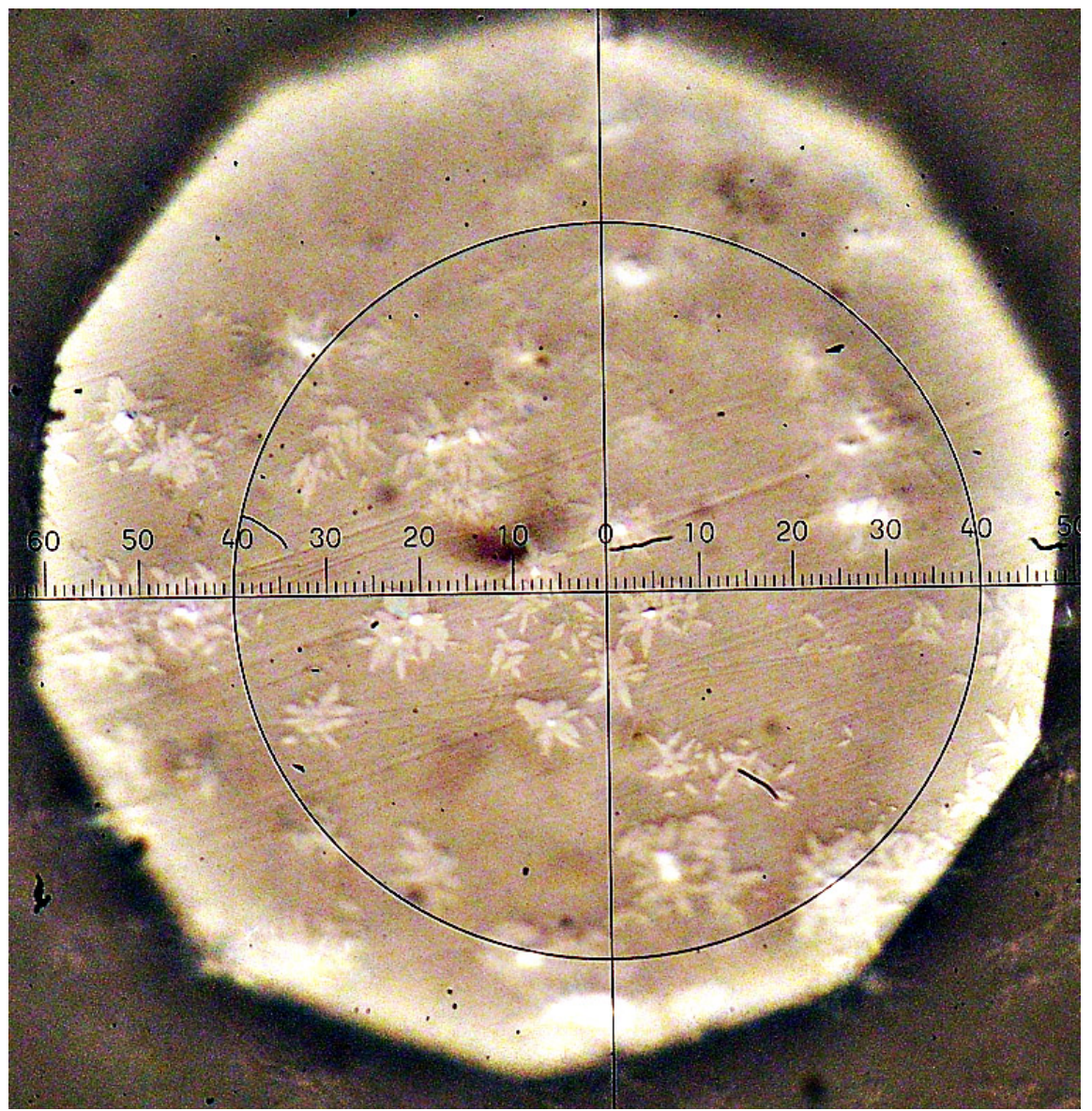

Figure 13. Optical photo of crystals of magnesiochromite (white centers) and diopside of outlet in glass I a. Thermal history: $740^{\circ} \mathrm{C} 4 \mathrm{~h}$ - for the nucleation of magnesiochromite and $750^{\circ} \mathrm{C}$ for $4 \mathrm{~h}+880^{\circ} \mathrm{C} 20 \mathrm{~min}$ - for the nucleation and development of diopside. Graduation is $1 \mu$.

$n=N_{\mathrm{S}} /\left(S \cdot D_{\mathrm{av}}\right)$, где $-D_{\mathrm{av}}=\left(D_{1}+D_{2}\right) / 2 .\left(D_{1}\right.$ и $D_{2}$ are the maximum and minimum dimensions of the crystal traces on the section.) Note that upon calculation of the crystals, the samples in which the crystals do not merge with each other were used.

Figure 14(a) shows the dependences of $n(t)$ for the emerging crystals of magnesiochromite at different temperatures.

As can be seen from Figure 14(a), the crystals were not found in the field of samples up to $t=10 \mathrm{~min}$. Then, dependences 1,7 , and 8 increase linearly in the time interval from 10 to $240 \mathrm{~min}$, dependence 2 increases $120 \mathrm{~min}$, dependences 3 and 6 up to $60 \mathrm{~min}$, and dependences 4 and 5 grow $30 \mathrm{~min}$. After the marked values of the time of the heat treatment, the growth of $n(t)$ slows. A further increase in the heating duration $t$ does not lead to an increase in the number of crystals of magnesiochromite $n(t)$ and the dependences $n(t)$ reach a certain saturation level specific for each temperature. One can see that the nucleation of the crystals of magnesiochromite occurs in the glass that is very different in composition from the composition of magnesiochromite; thus, their nucleation rate greatly depends on the time and therefore of the reduction of the amount of 


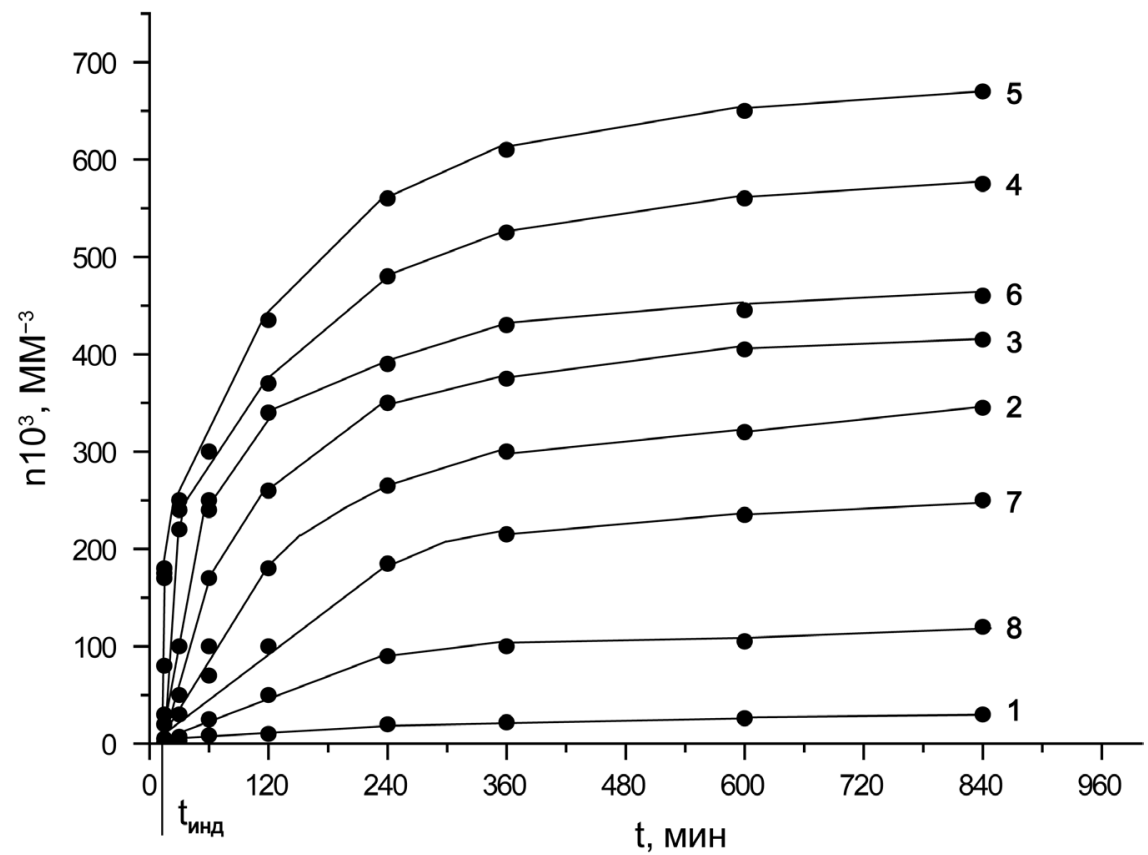

(a)

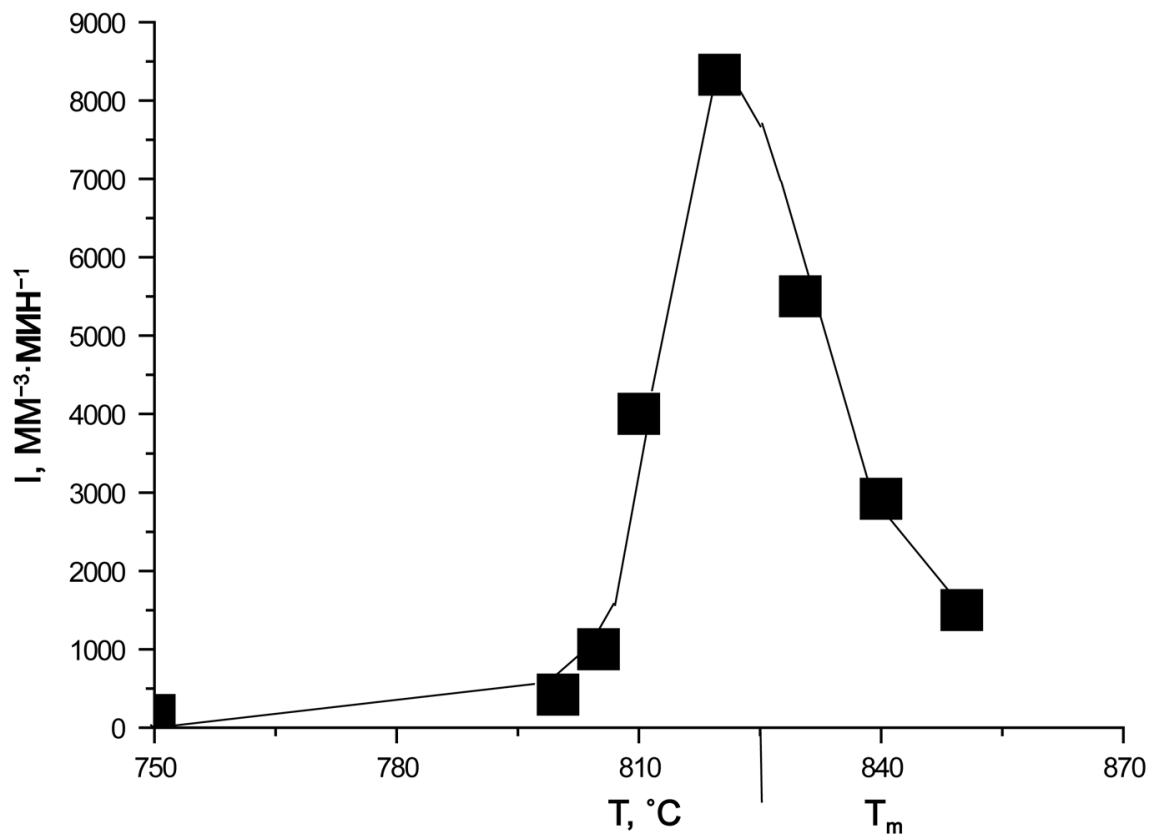

(b)

Figure 14. Dependence of the number of magnesiochromite crystals in glass I a on time (a), temperature dependence of the nucleation rate of magnesiochromite crystals (b). Heat treatment temperatures of glass $\left({ }^{\circ} \mathrm{C}\right): 750-1,800-2,805-3,810-4,820-5,830-$ $6,840-7,850-8$. (display at $880^{\circ} \mathrm{C}$ for $10 \mathrm{~min}$ ).

chromium oxide in the glass. This means that for the given temperature the magnesiochromite crystals were completely precipitated.

Using the data of Figure 14, the values of the stationary maximal nucleation rate of the magnesiochromite crystals were obtained from the slope of the $n(t)$ dependences at those time intervals where they increase linearly. 
Figure 14(b) shows the temperature dependence of the stationary maximum nucleation rate of the magnesiochromite crystals; it has the form of the maximum with the base width of $105^{\circ} \mathrm{C}$; and the maximum nucleation rate $I_{\mathrm{st}}\left(T_{\max }\right)$ is $8330 \mathrm{~mm}^{-3} \cdot \mathrm{min}^{-1}$ at $T_{\max }=825^{\circ} \mathrm{C}$.

The nonstationary nucleation time $t_{\text {ind }}$ for all temperatures is practically the same and of the order of $10 \mathrm{~min}$. Hence, the time of the induction period for the nucleation of the magnesiochromite crystals is $\tau=6 \mathrm{~min}$.

\subsubsection{Characteristics of the Volume Nucleation of the Catalyzed Phase of Diopside}

For the nucleation of diopside crystals, the original glass was first maintained at the temperature of the maximum nucleation rate of the magnesiochromite crystals $\left(820^{\circ} \mathrm{C}\right)$ for $14 \mathrm{~h}$ in order to precipitate all of the magnesiochromite (Figure 14 , curve 5). Next, the glass samples were subjected to heat treatments in the range of $800^{\circ} \mathrm{C}-870^{\circ} \mathrm{C}$ for a time period ranging from 0 to $20 \mathrm{~h}$. Figure 15 shows photographs of diopside crystals nucleated and grown in the glass on magnesiochromite crystals.

As can be seen from Figure 15, the degree of crystallinity of the glass increases with the duration of the isothermal exposure at $840^{\circ} \mathrm{C}$ and reaches $100 \%$ in $24 \mathrm{~h}$.

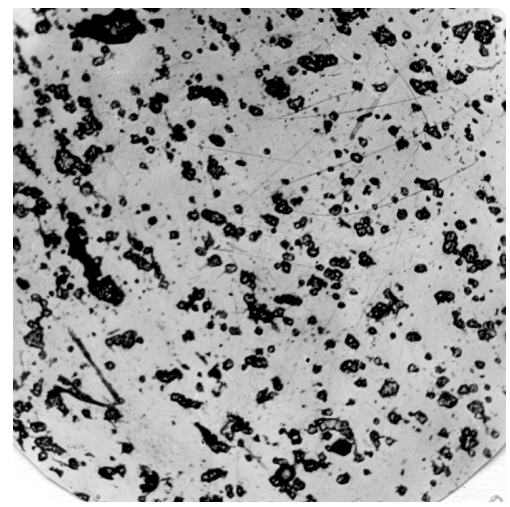

(a)

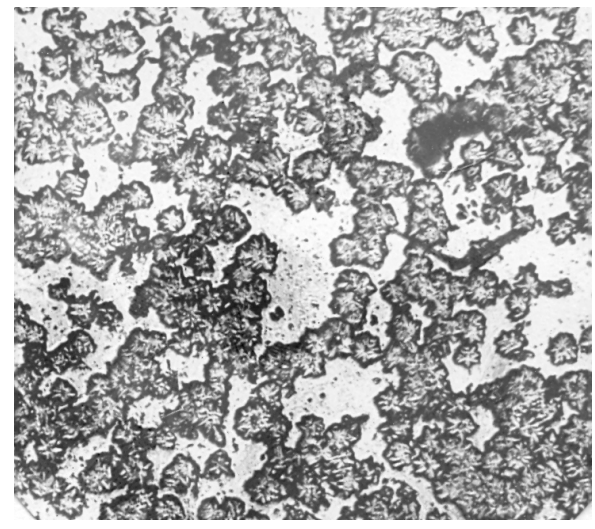

(d)

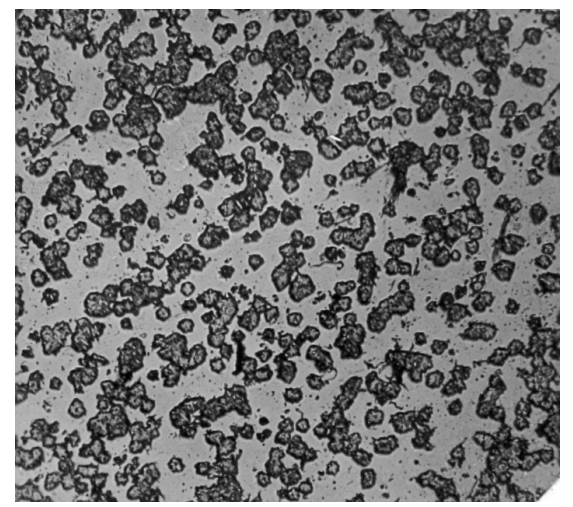

(b)

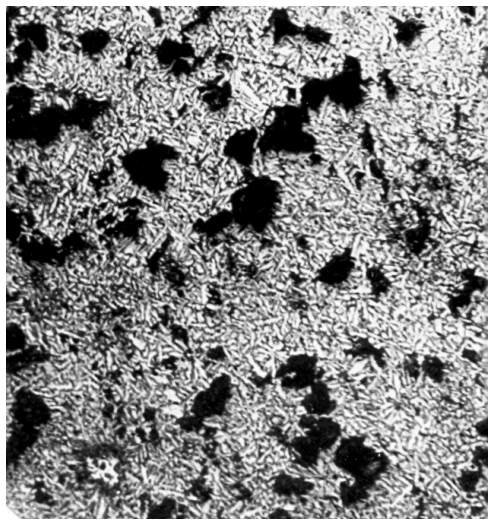

(e)

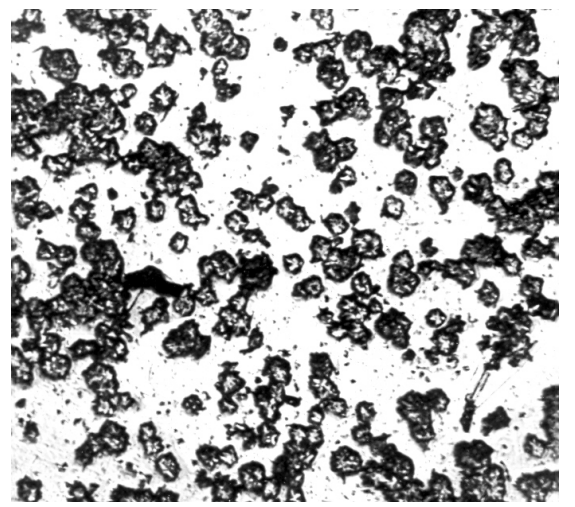

(c)

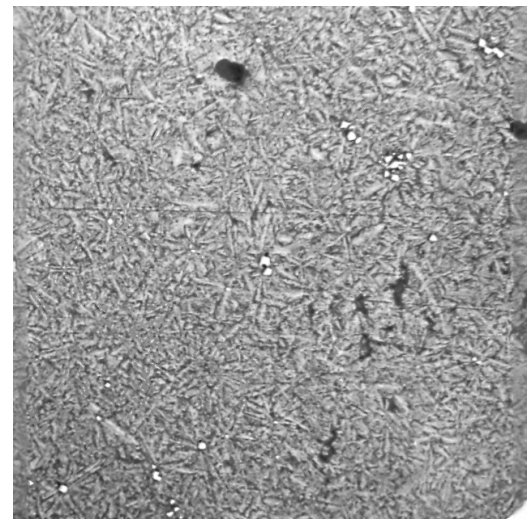

(f)

Figure 15. Photos of diopside crystals, nucleated and grown in the slag glass with the addition of 2 wt $\%$ of $\mathrm{Cr}_{2} \mathrm{O}_{3}$ at $\mathrm{T}=840^{\circ} \mathrm{C}$ for 2 - a, 5 - b, 8 - c, 12 - d, 16 - e, $24 \mathrm{~h}$ - $\mathrm{f}$ in the reflected light. Display mode is $880^{\circ} \mathrm{C}$ for $10 \mathrm{~min}$. Magnification $\mathrm{x} 138 \mathrm{k}$. The maximum size of crystals is $5 \mu \mathrm{m}$. 
Figure 16(a) shows the dependences of $n(t)$ for the nucleation of the diopside crystal at different temperatures.

As can be seen, the tendency for saturation most clearly manifests itself for curve 5, corresponding to $T=840^{\circ} \mathrm{C}$. The nucleation rate of the diopside crystals was obtained by formula $I \cong n / t$. Figure $16(\mathrm{~b})$ shows the temperature dependence of the nucleation rate of the diopside crystals and the maximum of the curve is located at a temperature of $=840^{\circ} \mathrm{C}$; moreover, $I\left(T_{\max }\right)=110 \mathrm{~mm}^{-3} \cdot \mathrm{min}^{-1}$.

As in the case of the curves, for the nucleation of magnesiochromite (Figure 16(a)), a tendency for saturation was also observed during the heat treatment time, i.e., the flattening of the curves.

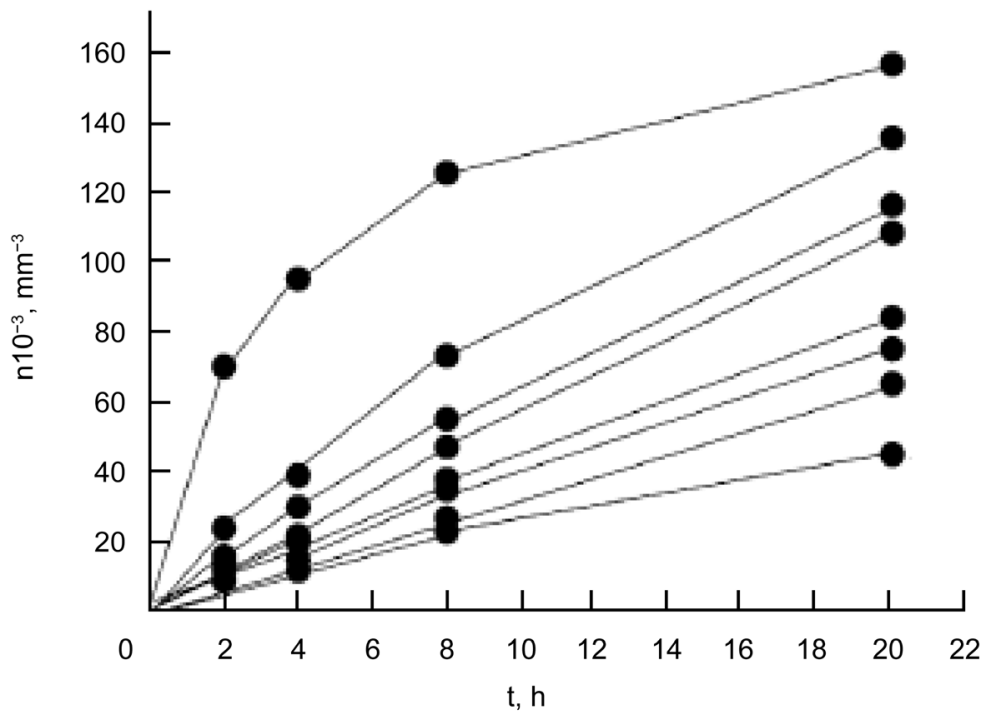

(a)

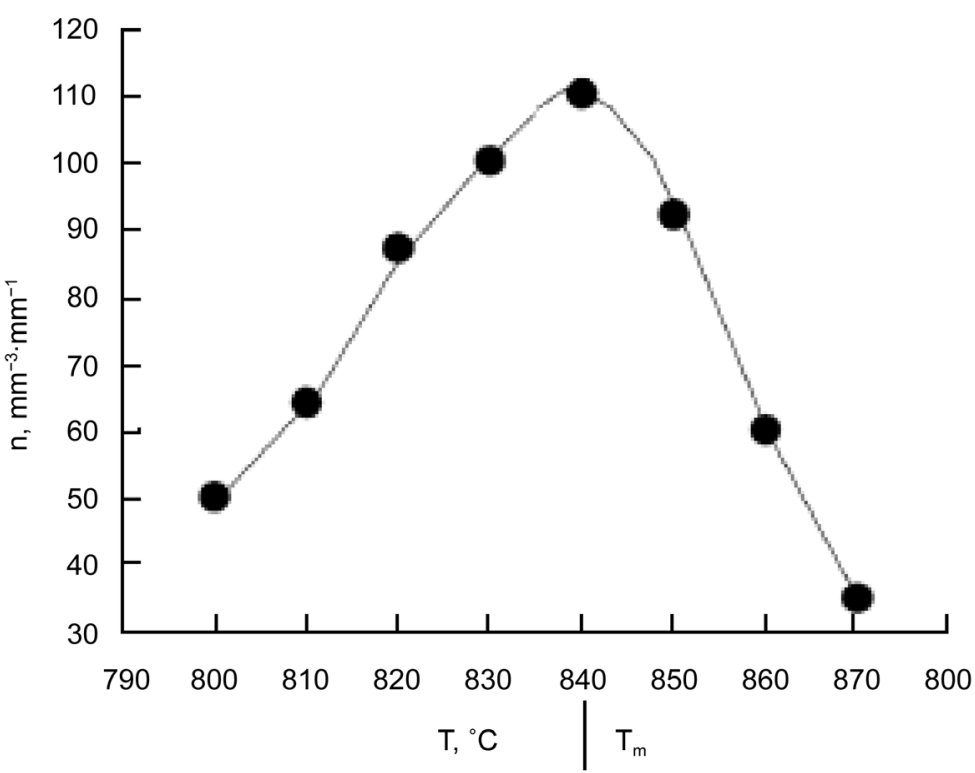

(b)

Figure 16. Dependence of diopside crystals in glass I a on time: for $800^{\circ} \mathrm{C}-1,810^{\circ} \mathrm{C}-2$, $820^{\circ} \mathrm{C}-3,830^{\circ} \mathrm{C}-4,840^{\circ} \mathrm{C}-5,850^{\circ} \mathrm{C}-6,860^{\circ} \mathrm{C}-7,870^{\circ} \mathrm{C}-8$; appearance at $880^{\circ} \mathrm{C}$ for $10 \mathrm{~min}(\mathrm{a})$; temperature dependence of the nucleation rate of diopside crystals (b). 
The number of magnesiochromite crystals $n_{M}$ that were not used as a catalyst in a unit volume can be written as

$$
n_{M}(t)=n_{M} \exp (-\alpha t), d n_{M}=-n_{M} \alpha d t,
$$

where $\alpha$ is the probability of the nucleation of spherulites diopside on a magnesiochromite crystal per unit time; it can be referred to as the catalytic activity of the magnesiochromite crystals with respect to diopside; and $\alpha$ depends on the ratio of the lattice cell parameters of the catalyst crystal of magnesiochromite ( $a$ $=8.333 \AA)$ and the crystal of the main phase of diopside $(b=8.926 \AA)$ emerging on it. As can be seen from the presented values of the $a$ and $b$ parameters, they are close o each other. Obviously, the nucleation rate of the diopside spherulites is $I=-d n_{M} / d t=\alpha n_{M}$. Consequently, decreases with time as does which leads to the form of the curves in Figure 16(a). The maximum $I$ for diopside (the catalyzing phase) is located at a temperature of $=840^{\circ} \mathrm{C}$, which is $20^{\circ} \mathrm{C}$ higher than $T_{\max }$ for magnesiochromite. The rate of the catalyzed nucleation of diopside $I$ is approximately proportional to the total number of magnesiochromite particles $n_{M}(T)$ and the average area of the surface of one particle $\bar{S}_{M} \quad\left(\bar{S}_{M}=4 \pi \bar{R}^{2}\right.$ where $\bar{R}$ is the mean radius of the particle), and reaches in the maximum the value of $110 \mathrm{~mm}^{-3} \cdot \mathrm{min}^{-1}$. It can be associated both with the change in the glass composition in the crystallization process of diopside and the gradual actuation of the centers of the nucleation of diopside-of the magnesiochromite crystals similar to the process described earlier in the article when discussing the features of nucleation of the melilite crystals on perovskite. Table 6 shows the maximum values of the rates of nucleation and growth of the magnesiochromite and diopside crystals.

As can be seen from the data presented in Figure 14 and Figure 16 and in Table 6, the positions of the maxima of the temperature dependences of the stationary nucleation rates of the catalyzing and catalyzed phase are spread out on the temperature scale and are spaced $15^{\circ} \mathrm{C}$ apart from each other. The maxima of the growth rates are $850^{\circ} \mathrm{C}$ (for magnesiochromite) and $960^{\circ} \mathrm{C}$ (for diopside) are moved relative to each other by $110^{\circ} \mathrm{C}$. The maximum of the nucleation rate of magnesiochromite is distant from the maximum of the magnesiochromite growth rate by $25^{\circ} \mathrm{C}$ and the maximum of the nucleation rate of diopside is distant from the maximum of the diopside growth rate by $120^{\circ} \mathrm{C}$. The presence of the temperature range between the maximum values of the nucleation and growth rates of the magnesiochromite and diopside crystals makes it possible to

Table 6. Maximum values of the rate of nucleation and growth of magnesiochromite and diopside crystals.

\begin{tabular}{|c|c|c|c|c|c|c|c|}
\hline \multicolumn{4}{|c|}{ Magnesiochromite } & \multicolumn{4}{|c|}{ Diopside } \\
\hline \multicolumn{2}{|c|}{ nucleation } & \multicolumn{2}{|c|}{ growth } & \multicolumn{2}{|c|}{ nucleation } & \multicolumn{2}{|c|}{ growth } \\
\hline $\begin{array}{l}T_{m}, \\
{ }^{\circ} \mathrm{C}\end{array}$ & $\begin{array}{c}I_{s t}\left(T_{m}\right), \\
\mathrm{mm}^{-3} \cdot \mathrm{min}^{-1}\end{array}$ & $\begin{array}{l}T_{m}, \\
{ }^{\circ} \mathrm{C}\end{array}$ & $\begin{array}{c}U_{m}, \\
\mathrm{~cm} / \mathrm{s}\end{array}$ & $\begin{array}{l}T_{m}, \\
{ }^{\circ} \mathrm{C}\end{array}$ & $\begin{array}{c}I_{s t}\left(T_{m}\right), \\
\mathrm{mm}^{-3} \cdot \mathrm{min}^{-1}\end{array}$ & $\begin{array}{l}T_{m}, \\
{ }^{\circ} \mathrm{C}\end{array}$ & $\begin{array}{c}U_{m} \\
\mathrm{~cm} / \mathrm{s}\end{array}$ \\
\hline 825 & 8330 & 850 & $0.23 \times 10^{-6}$ & 840 & 110 & 960 & $11.1 \times 10^{-6}$ \\
\hline
\end{tabular}


obtain glass-ceramic materials according to the glass-ceramics technology. However, there are areas in which the maxima of the $I(T)$ and $U(T)$ curves for magnesiochromite and diopside overlap. This fact should be considered when selecting the heat treatment mode of glass to avoid coarse crystallization. In the preparation of finely dispersed slag glass-ceramics, it is necessary to keep glass first at $800^{\circ} \mathrm{C}$ for $14 \mathrm{~h}$, which is required to achieve the complete precipitation of the magnesiochromite crystals, and then at $T=900^{\circ} \mathrm{C}$, located below the temperature, corresponding to the maximum growth rate of diopside to avoid the consolidation of the nucleated crystals of the main phase (coarse crystallization).

As was shown in [31], in the glass-forming systems, two cases of heterogeneous nucleation are possible. The first case is on the catalyst's particles with a radius smaller than the critical nucleus of the catalyzing phase. The second case is on the catalyst's particles with a radius larger than the critical nucleus of the catalyzing phase. In the first case, the position of the maximum rate of the catalyzed nucleation remains unchanged, while in the second phase, it leads to a temperature shift of the maximum rate of the catalyzed nucleation compared to spontaneous nucleation. Thus, the second case is implemented in our research for the bulk heterogeneous nucleation of crystals in glass based on the furnace slag.

\subsection{Results and Discussion of Volume Nucleation in Glasses with $\mathrm{Cr}_{2} \mathrm{O}_{3}$ Content}

Glass based on the furnace slag of the Chelyabinsk metallurgical complex is obtained. It is established that the introduction of $\mathrm{Cr}_{2} \mathrm{O}_{3}$ allows achieving volumetric crystallization of slag glass and the optimum quantity of the $\mathrm{Cr}_{2} \mathrm{O}_{3}$ catalyst is $2 \mathrm{wt} \%$ above 100. It is established that the volume nucleation of the crystals is due to the occurrence of two basic processes. The first is the process of the formation of the crystallization centers. It consists in the formation of the metastable spinel phase of magnesiochromite, which is the catalyst for the formation of the main catalyzing crystalline phase of diopside.

A separate study of the temperature dependences of the rates of nucleation and growth of the catalyzing phase of magnesiochromite and of the main phase of diopside is performed. The parameters of the volumetric nucleation of the crystals of the catalyzing and catalyzed phases are determined: the temperature dependences of the nucleation rate of the crystals and the values of the growth rate of the crystals for the temperatures of the maximum of the growth rate. It is found that for the studied glass, the times of nonstationary nucleation are very short-about $6 \mathrm{~min}$. The maximum values of the nucleation rates of the crystals of the catalyzing and catalyzed phase are determined.

On the example of the crystallization of magnesiochromite and diopside, the full Tamman curves for the glass of a complex industrial composition are constructed, and the ways that allow one to reduce the search time of the chemical composition and time temperature conditions of the crystallization upon the development of rational technology for obtaining glass-ceramic materials are shown. 
It is established that an increase in the number of magnesiochromite by more than $2.5 \mathrm{wt} \%$ above $100 \%$ to $10 \mathrm{wt} \%$ above $100 \%$, allows one to get glass with a pattern of malachite with varying degrees of coloration of the glass monolith and glass crystalline material, with diverse malachite patterns by crystallizing the glass in the temperature range of the maximum of the nucleation rate of the magnesiochromite crystals.

Thus, it is shown that the slags of the Urals Nizhny Tagil Metallurgical Plant can be used as the raw material for obtaining glass and glass-crystalline materials of a wide range of green shades with a malachite pattern. This can help reduce the slag heaps and weakening of the technogenic exposure factors on the environment.

\section{Surface Crystallization of Glass Based on Blast Furnace Slags}

One of the works on recycling blast furnace slag is their use as the primary basis of mineral raw materials, which are used to produce glass and slag glass-ceramics. As shown above glass obtained by the additional charging of real metallurgical slags by silica generally possesses surface crystallization: it has a low nucleation rate in volume and high nucleation rate on the glass surface. The volume nucleation of the crystals of the catalyzing phase of the perovskite and catalyzed phase of melilite and catalyzing phase of the $\mathrm{Cr}_{2} \mathrm{O}_{3}$ and catalyzed phase of diopside was studied above. Now we will focus on the surface nucleation of crystals in glass derived from blast furnace slags, which is most often found in the glass of complex multicomponent systems [32]-[50].

Glass in accordance with the DTA data (Figure 3) was heat-treated in the temperature range of $700^{\circ} \mathrm{C}-1000^{\circ} \mathrm{C}$ for various times. The temperatures of all the effects increase with the increasing silica content in glass, and the melting range is expanded. Only one of the nine types of glass synthesized, III a (with the following ratio of the main components: $\mathrm{TiO}_{2}: \mathrm{CaO}: \mathrm{MgO}: \mathrm{Al}_{2} \mathrm{O}_{3}: \mathrm{SiO}_{2}=1: 7.2: 1.8$ : 2.6:7.4), underwent bulk crystallization. At $600^{\circ} \mathrm{C}$ in the volume of this glass, a spinel-like phase of perovskite $\mathrm{CaO} \cdot \mathrm{TiO}_{2}$ (PCPDFWIN, card 83-231) was formed as a result of the interaction of titanium and calcium oxides, which then served as a catalyst for the volume nucleation of melilite (solid solution of gehlenite $2 \mathrm{CaO} \cdot \mathrm{Al}_{2} \mathrm{O}_{3} \cdot \mathrm{SiO}_{2}$ in akermanite $2 \mathrm{CaO} \cdot \mathrm{MgO} \cdot 2 \mathrm{SiO}_{2}$ ) in the temperature range of $840^{\circ} \mathrm{C}-1100^{\circ} \mathrm{C}$. The crystals of melilite were nucleated both on the glass surface (and then grew in the sample) and the volume. The crystals of diopside were nucleated only on the surface. The volume catalyzed nucleation of melilite crystals on perovskite is considered above. This part focuses only on the surface crystallization of melilite and diopside, which was observed in all nine types of glass.

To eliminate the influence of the dispersion degree on the crystallization processes and to make the results comparable, in the crystallization study, powders of the same degree of dispersion were used-a fraction with a particle size of $0.050<d<0.065 \mathrm{~mm}$. When crystallization was studied by XRPA, powd- 
ers of the glass of this dispersion were heat treated, and before the X-ray study they were ground to a finely divided state.

XRPA of the powders of glass of series II (Figure $17(\mathrm{a})$ ), heat treated at $850^{\circ} \mathrm{C}$ (corresponding to the beginning of the first crystallization peak $T_{\text {cr } 1}$ ), showed that the crystallization starts from the simultaneous formation of melilite on the glass surface (solid solution of gehlenite $2 \mathrm{CaO} \cdot \mathrm{Al}_{2} \mathrm{O}_{3} \cdot \mathrm{SiO}_{2}$ in akermanite $2 \mathrm{CaO} \cdot \mathrm{MgO} \cdot 2 \mathrm{SiO}_{2}$ ) (PCPDFWIN, card 79-2423) and diopside $\mathrm{CaO} \cdot \mathrm{MgO} \cdot 2 \mathrm{SiO}_{2}$ (PCPDFWIN, card 83-1820).

At temperatures above $850^{\circ} \mathrm{C}$ (but in the vicinity of $T_{\text {crl }}$ ), melilite grows significantly faster than diopside. The formation rate of diopside increases noticeably only when the temperature approaches $T_{\mathrm{cr} 2}$. Surface crystallization of melilite begins near the glass transition temperature for the studied glass $\left(730^{\circ} \mathrm{C}\right.$ $770^{\circ} \mathrm{C}$ ). With increasing temperature, under the action of the surface tension forces, the glass loses its original shape and it melts slightly. Figure 17(b) shows the appearance of the crystalline crust growing from the surface into the sample.

The crystalline crust thickness increases with the time of the isothermal exposures.

\subsection{Study of the Dependence of the Crystal Growth Rate on Temperature}

For all of the glass studied, the dependences of the growth rate of the crystalline crust on the glass surface on temperature were determined (Figure 18).

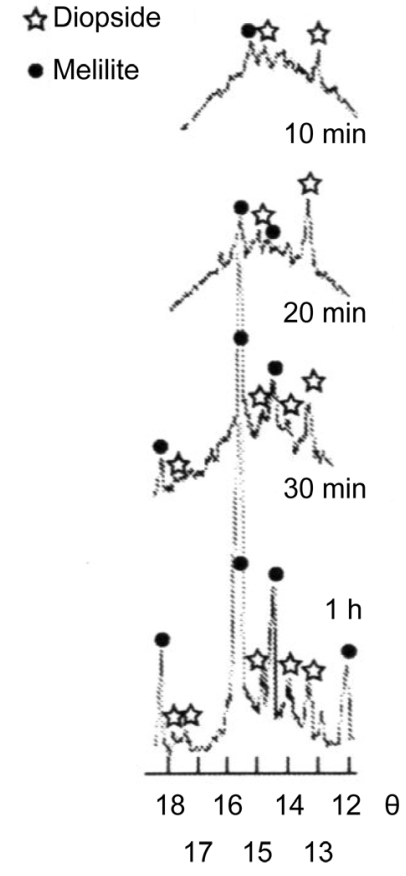

(a)

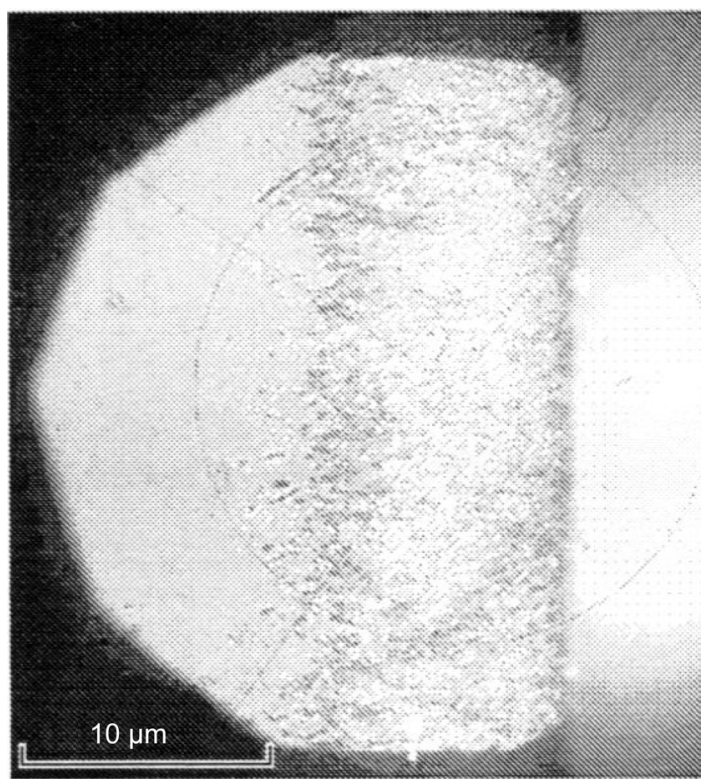

(b)

Figure 17. Diffractograms of powders of glass II a at $\mathrm{T}=850^{\circ} \mathrm{C}(\mathrm{a})$; appearance of crystalline crust, which has grown from the surface into the sample at $\mathrm{T}=850^{\circ} \mathrm{C}$ for $30 \mathrm{~min}$ (b). The numbers of the X-ray patterns are the heat treatment time. Thermal history of perovskite: $740^{\circ} \mathrm{C}$ for $24 \mathrm{~h}$. 
For comparison with the growth rates of the crystalline crust, Figure 18 (3) shows the dependence of the crystal growth rate of perovskite $\mathrm{CaO} \cdot \mathrm{TiO}_{2}$ in glass III $a$ (the only one of the nine compositions in which volumetric nucleation of melilite crystals on perovskite was found). In this glass, two kinds of nucleation were observed: surface nucleation of melilite and diopside (curves $a-c$ ) and volumetric nucleation of the perovskite crystals (curve $d$ ). The perovskite crystal growth rate is obtained with the processing of the electron microscopic image shown in Figure 9. Figure 18 shows that in the slag glass, the value of the growth rate from the surface into the sample is in orders of magnitude higher than the growth rate in the volume.

Using the data of Figure 18, the dependences of the growth rate logarithm of the crystalline crust on the inverse temperature $1 / T(\mathrm{~K})$ for glass I $a$, I $b$, I $c$, II $a$, II $b$, II $c$, III $a$, III $b$, and III $c$ were calculated. The activation energy values of the growth rate $E_{U}$ of the crystals formed on the surface of the samples and growing into the samples are presented in Table 7.

As can be seen from Table 7, with an increase of the amount of $\mathrm{SiO}_{2}$ in the glass the values increase. This demonstrates the deterioration of the crystalline ability of glass with the increasing content of glass forming oxides. The closeness in the values of the activation energy of the crystal growth reflects their closeness in chemical composition. The difference in the content of the oxides of calcium and titanium affects the values.

\subsection{The Values of Density, Strength Characteristics, and Elastic Properties of the Synthesized Glass}

The values of density, strength characteristics, and elastic properties of the

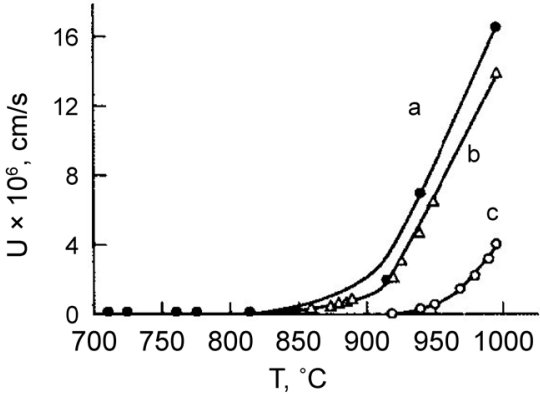

1

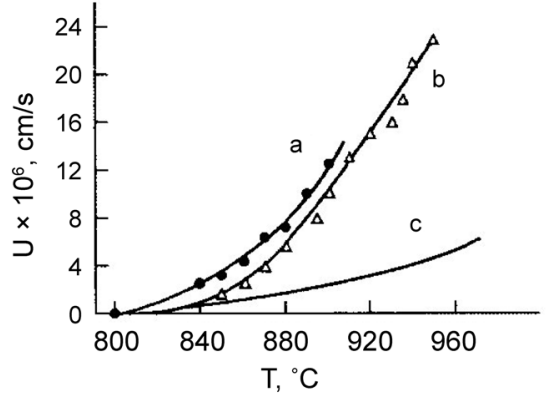

2

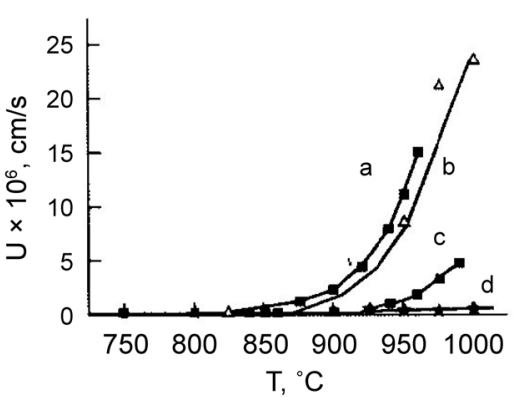

3

Figure 18. Dependences of the crystalline crust growth rate on temperature for glass based on slags: I (1), II (2), and III (3). Notations of curves $\mathrm{a}, \mathrm{b}, \mathrm{c}$ in the figures correspond to glass compositions in Table 1 ; $\mathrm{d}$ is the volumetric nucleation of perovskite crystals for the glass from slag III.

Table 7. The activation energy values of the crystal growth rate $\left(E_{U}\right)$ for glass from slags I, II, III.

\begin{tabular}{cccccc}
\hline \multicolumn{5}{c}{$E_{u} \mathrm{kcal} / \mathrm{mol}$} \\
\hline I $a$ & 90 & I $b$ & 95 & I $c$ & 167 \\
II $a$ & 84 & II $b$ & 94 & II $c$ & 166 \\
III $a$ & 90 & III $b$ & 92 & III $c$ & 96 \\
\hline
\end{tabular}


synthesized glass are shown in Table 8 and Table 9 in comparison to the window glass.

The values in Table 8 were determined in accordance with GOST 9900-2013. The error is not more than $1 \%$.

To determine $E$, $G$, and $\sigma$, the following formulas were used:

$$
G=\rho V_{t}^{2}, \sigma=\frac{1}{2}\left(\frac{\alpha^{2}-2}{\alpha^{2}-1}\right), \alpha=\frac{V_{l}}{V_{t}}, E=2 G(1+\sigma) .
$$

Here $V_{l}$ is the sound velocity of the longitudinal wave, $V_{t}$ is the sound velocity of the shear wave, $\rho$ is density, $E$ is Young's modulus, $g$ is the shear modulus, and $\sigma$ is Poisson's ratio.

The data in Table 8 indicate the advantages of glass slags over the window glass and the possibility of their wide use in industry, such as glass containers of different colors ranging from light yellow to dark brown with a reddish tinge. The main advantage of slag glass over window glass is that using slag wastes as the feedstock contributes to the reduction of slag heaps and eases the technogenic impact factors on the environment.

\subsection{Powder Technology for Producing Glass-Ceramic Materials from Slag Glass}

Glass, having only surface crystallization, may be converted into a monolith with quasi-volume crystallization by grinding the original glass into powder and heating it in the range of softening temperatures, where the maximum nucleation rate of crystals lies for many types of glass. Upon exposure of glass close to

Table 8. Density and strength characteristics of synthesized glass and window glass.

\begin{tabular}{cccc}
\hline Composition & Density, $\mathrm{g} / \mathrm{cm}^{3}$ & Impact elasticity, $\mathrm{kg} / \mathrm{cm}^{2}$ & Bending strength, $\mathrm{kg} / \mathrm{cm}^{2}$ \\
\hline I $a$ & 2.920 & 1.5 & 162 \\
I $b$ & 2.779 & 1.6 & 160 \\
I $c$ & 2.694 & 1.5 & 150 \\
II $a$ & 2.913 & 1.6 & 110 \\
II $b$ & 2.786 & 1.6 & 112 \\
II $c$ & 2.672 & 1.7 & 114 \\
III $a$ & 2.948 & 3.0 & 146 \\
III $b$ & 2.816 & 2.8 & 150 \\
III $c$ & 2.697 & 2.1 & 140 \\
Window glass & 2.5 & 2.0 & - \\
\hline
\end{tabular}

Table 9. Elastic properties of synthesized glass.

\begin{tabular}{cccc}
\hline Glass & Young's modulus, $E, \mathrm{~kg} / \mathrm{mm}^{2}$ & Shear modulus, $G, \mathrm{~kg} / \mathrm{mm}^{2}$ & Poisson coefficient, $\sigma$ \\
\hline II $b$ & 10965 & 4225 & 0.30 \\
II $c$ & 11330 & 4365 & 0.30 \\
\hline
\end{tabular}


the glass transition temperature $\left(T_{g}\right)$ on the surface of glassy particles, the nucleation of crystals starts to occur. Simultaneously, the particles fuse into each other due to the action of the surface tension forces and the reduction of the viscosity of glass. As a result of these processes, glass crystalline volume-crystallized material is obtained in the form of a monolith. If the crystals nucleating on the glass surface quickly grow into the depth of the glass, then the degree of crystallinity of the glass depends on the degree of dispersion of the particles of the initial crushed glass. Monoliths of the source glass were crushed, fractionated, and then the fractions were subjected to two-stage heat treatment. By changing the treatment temperature in the first stage glass crystalline material of two forms was obtained: porous material with a pore size of $0.05 \mathrm{~mm}$ and sintered material in the form of a nonporous monolith. In the first case, the material properties are determined by the diopside crystals bonded with a glass-forming layer; in the second case, by melilite, diopside, and a small amount of glass [5]. The study of the nucleation of crystals in glassy powders derived from slags from Nizhny Tagil allowed establishing time-temperature regimes for obtaining materials by sintering powders of porous and monolithic body-crystallized glass.

Figure 19 shows the relative content of melilite and diopside in different modes of heat treatment.

Figure 20 shows the appearance of the samples prepared by sintering the powders of glass I $a$ and I $b$, as well as a picture of the porous material based on the crystallized glass I $b$.

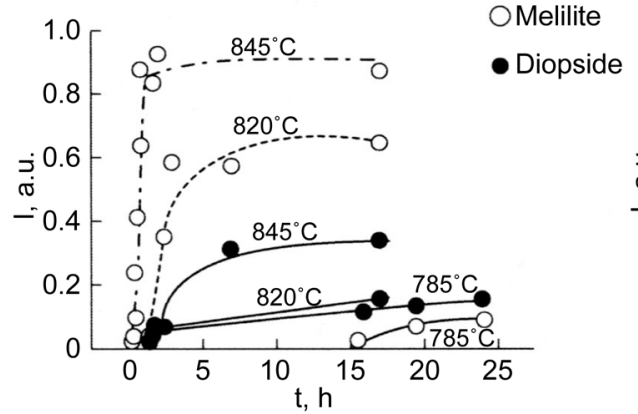

(a)

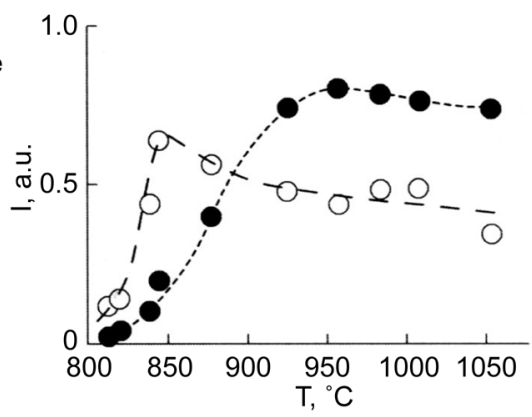

(b)

Figure 19. The dependence of the formation intensity of melilite and diopside on heat treatment time at temperatures (a) and on temperature for a treatment time of $10 \mathrm{~h}$ (b) for glass I a. Melilite-hollow circles, diopside-filled. $0.050<\mathrm{d}<0.065 \mathrm{~mm}$.

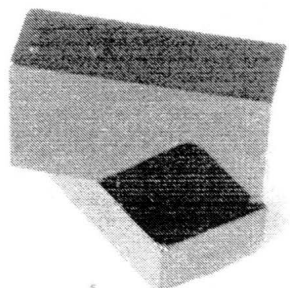

(a)

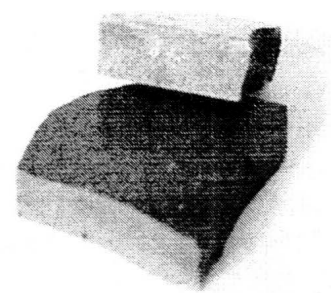

(b)

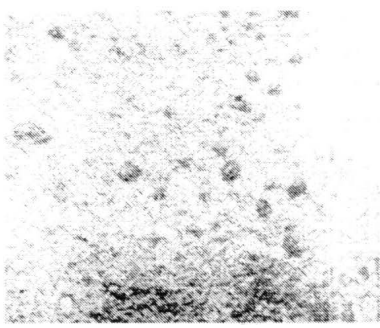

(c)

Figure 20. The appearance of samples prepared by sintering powders of glass I $a$ (a), I $b$ (b); picture of porous material based on crystallized glass I $b$; (c). Zoom. 300. 


\subsection{Results and Discussion of Surface Nucleation}

According to the Ostwald rule, the phase with the highest nucleation rate is the first to fall. On the way to the formation of the critical nucleus of this phase, the lowest energy barriers are overcome. The nuclei of this phase are most easily obtained from the glass by the diffusion displacement of the atoms and further structural streamlining at relatively low temperatures. Slag glass is extremely complex in composition and solid solutions are easily formed in it, particularly, of the melilitic type. According to the data in Figure 19, one can judge the relative content of the crystalline phases. Such data can be very useful when selecting the modes of the heat treatment of glass in the preparation of glass ceramics using powder technology.

The kinetic curves in Figure 19(a) characterize the sequence of the formation of diopside and melilite at three temperatures: $T_{1}=785, T_{2}=820$ and $T_{3}=$ $845^{\circ} \mathrm{C}$. At $T_{1}$ diopside appears first, while at $T_{2}$ diopside with melilite fall simultaneously. With an increase of the isothermal exposure of the glass, melilite crystals are formed more than diopside crystals. At $T_{3}$ melilite is already considerably larger than diopside. Its amount sharply increases in the first quarter of an hour, while diopside becomes noticeable only after an hour's exposure.

As was shown in [26], near $T=960^{\circ} \mathrm{C}$, in the studied glass based on slags, intensive crystallization of diopside takes place with high rates of nucleation and crystal growth; thus, the exposure of the glass powders of the noted dispersity at temperatures close to $960^{\circ} \mathrm{C}$ leads to rapid crystallization. This result in gray porous material with a pore size of up to $0.5 \mathrm{~mm}$ composed of diopside and a layer from the remaining uncrystallized part of the glass.

At a temperature of $860^{\circ} \mathrm{C}$ for $20 \mathrm{~min}$, the powder is sintered into a dark gray monolith (the main crystalline phase-melilite) with glass layers. Increasing the time of the heat treatment at $860^{\circ} \mathrm{C}$ or raising the temperature to $1000^{\circ} \mathrm{C}$ leads to the deposition of diopside from the glassy layer-the sintered material acquires a light gray color. The sintered materials are a dense gray monolith without pores. Upon crystallization in powders, the effect of a declining degree of crystallinity $\alpha$ is observed with a decrease of the particle size of the powder. It may be due to the fact that at temperatures well above the glass transition temperature $T_{g}$ of the original glass, simultaneously with the crystallization, the viscous flow and fusion of the particles due to their surface tension take place. The smaller the particle size the greater the number of contacts between them in the sample. It promotes the fusion of the particles and reduces their free surface over time, which catalyzes the nucleation of the crystals. As a result of the fusion process of the fine particles upon softening of the glass, a monolithic polycrystal is formed.

\section{Conclusions}

It is found that slag glass generally has surface crystallization. Grinding, fractionation, and a study of the surface crystallization of powders of various fractions are performed. It is found that at low temperatures, melilite falls first, followed by diopside; in contrast, at high temperatures, diopside falls out first, followed by 
melilite. The method of converting slag glass into a monolith with quasi-volume crystallization is proposed by grinding the original glass and heating it in the softening temperature range, which is where the maximum nucleation rate of crystals for many types of glass lies.

Added number of crystalline compounds of the glass forming systems for which the basic nucleation characteristics are determined for the volume of homogeneous and/or heterogeneous nucleation and which form the basis for the development of the theory of a new phase nucleation in condensed systems. There are perovskite, melilite, magnesiochromite and diopside, which nucleated in complex multicomponent glasses based on blast furnace slag.

\section{References}

[1] Sycheva, G.A. (2016) Crystal Growth and Nucleation in Glasses in the Lithium Silicate System. Journal of Crystallization Process and Technology, 6, 29-55.

[2] Ionchenkova, I. (1981) Glass, Glass-Ceramics, and Slag. Khim Zhizn, 11, 36-38.

[3] Ostrov, E.I., Vinokurov, Y.V. and Tikhonov, V.I. (2003) Utilization of Metallurgical Slags-A Reserve of Economics. Rynok vtorichnykh metallov, 6, 66-68.

[4] Khan, B.K. (1975) Problems of Production and Application of Stone Casting in the National Economy. Probl Kamen Lit ya, No. 3, 3-22.

[5] Pavlushkin, N.M. (1970) Fundamentals of the Technology of Glass-Ceramics. Stroiizdat, Moscow.

[6] Zhunina, L.A., Kuzmenkov, M.I. and Yaglov, V.N. (1974) Pyroxene Glass-Ceramics. Belarusian State University, Minsk.

[7] Pavlushkin, N.M., Sarkisov, P.D., Orlova, L.A., Kondakova, N.G., Zhurba, E.N. and Egorova, L.S. (1974) Investigation of the Crystallization Properties of High Temperature Slag Glasses. In: Structure and Properties of Glass-Crystalline Materials Based on Rock and Waste, The Academy of Sciences of KazSSR, Chimkent, 212213.

[8] Pavlushkin, N.M., Beletskii, B.I. and Motsareva, E.G. (1974) Influence of the Effect of Phase Stabilization on the Process of Crystallization of Glasses in the $\mathrm{CaO}-\mathrm{MgO}-\mathrm{Al}_{2} \mathrm{O}_{3}-\mathrm{SiO}_{2}$ System. In: Structure and Properties of Glass-Crystalline Materials Based on Rock and Waste, The Academy of Sciences of KazSSR, Chimkent, 3-10.

[9] Barantseva, S.E. and Kostyunin, Y.M. (1974) Investigation into the Influence of Specific Types of Stimulators on Ceramization of Glasses of the Pyroxene Composition. Steklo Sitally Silik Mater, No. 3, 215-219.

[10] Pavlushkin, N.M., Sarkisov, P.D., Levina, V.S., Roginskaya, Y.E. and Kondakova, N.G. (1975) Petrographic Investigations of the Process of Crystallization of Glasses with an Increased Content of Iron Oxides. Probl Kamen Lit ya, No. 3, 77-79.

[11] Zhunina, L.A., Dashchinskii, L.G., Uakhbe, A.M., Barantseva, S.E. and Kostyunin, Y.M. (1974) On the Mechanism of Crystallization of Glasses of the Pyroxene Composition Produced from Rock. In: Structure and Properties of Glass-Crystalline Materials Based on Rock and Waste, The Academy of Sciences of KazSSR, Chimkent, 46-51.

[12] Zhunina, L.A., Kostyunin, Y.M., Dashchinskii, L.A., Babushkin, O.S., Tomchina, T.I., Barantseva, S.E. and Pashkevich, V.N. (1982) Investigation of the Mechanism of Directional Crystallization of Glasses of the Pyroxene Composition. In: Catalyzed Crystallization of Glasses, GIS, Moscow, 100-105. 
[13] Mel'nichenko, T.D., Rizak, V.M., Mel'nichenko, T.N. and Fedelesh, V.I. (2004) Parameters of the Theory of Fluctuation Free Volume for Glasses in the Ge-As-Se System. Glass Physics and Chemistry, 30, 406-414.

https://doi.org/10.1023/B:GPAC.0000045920.01447.ba

[14] Pavlushkin, N.M. (1983) Chemical Technology of Glass and Glass-Ceramics. Stroiizdat, Moscow.

[15] Mazurin, O.V., Roskova, G.P., Aver'yanov, V.I. and Antropova, T.V. (1991) Two-Phase Glasses: Structure, Properties, and Applications. Nauka, Leningrad.

[16] Glagolev, A.A. (1941) Geometric Methods for Quantitative Analysis of Aggregates under the Microscope. Gosgeolizdat, Moscow.

[17] Mel'nichenko, L.G. and Pavlova, V.N. (1970) Investigation of the Separation of Slag Glass and Its Influence on the Process of Ceramization. In: Bondarev, K.T., Pavlushkin, N.M., Kozlovskii, V.S., Minakov, A.G., Minakov, V.A. and Strekalov, A.V., Eds., Slag Glass-Ceramics, Stroiizdat, Moscow, 21-26.

[18] Lapin, V.V. (1938) Phase Separation of the Silicate Melt in the Metallurgical Slag. Proceedings of the Institute of petrography of the USSR Academy of Sciences, 13, 247.

[19] Sycheva, G.A. and Polyakova, I.G. (2013) Volume Nucleation of Crystals in Glass Based on Blast-Furnace Slag. Glass Phys. Chem., 39, 248-260. https://doi.org/10.1134/S1087659613030218

[20] Sycheva, G.A. and Polyakova, I.G. (2016) Surface Nucleation of Crystals in Glass Based on Blast-Furnace Slag. Glass Physics and Chemistry, 42, 372-378. https://doi.org/10.1134/S1087659616040131

[21] Rincon, J.M., Gonzalez-Oliver, C.J.R. and James, P.F. (1988) Phase Separation in $\mathrm{Li}_{2} \mathrm{O}-\mathrm{SiO}_{2}$ Glasses with Additions of $\mathrm{V}_{2} \mathrm{O}_{5}, \mathrm{MnO}_{2}$ and $\mathrm{Cr}_{2} \mathrm{O}_{3}$. Journal of Materials Science, 23, 2512-2516. https://doi.org/10.1007/BF01111910

[22] Shen, D.K. and Orlova, L.A. (1989) Mechanism of the Catalytic Effect of $\mathrm{Cr}_{2} \mathrm{O}_{3}$ on the Crystallization of Glasses. Journal of Non-Crystalline Solids, 112, 207-210.

[23] Barbieri, L., Leonelli, C., Manfredini, T., Pellacani, G.C., Siligardi, C., Tondello, E. and Bertoncello, R. (1994) Solubility, Reactivity and Nucleation Effect of $\mathrm{Cr}_{2} \mathrm{O}_{3}$ in the $\mathrm{CaO}-\mathrm{MgO}-\mathrm{Al}_{2} \mathrm{O}_{3}-\mathrm{SiO}_{2}$ Glassy System. Journal of Materials Science, 29, 62736280. https://doi.org/10.1007/BF00354571

[24] Marghussian, V.K. and Arjomandnia, S. (1999) Crystallisation Behaviour of $\mathrm{SiO}_{2}-$ $\mathrm{Al}_{2} \mathrm{O}_{3}-\mathrm{CaO}-\mathrm{MgO}-\left(\mathrm{R}_{2} \mathrm{O}, \mathrm{Fe}_{2} \mathrm{O}_{3}, \mathrm{TiO}_{2}\right)$ Glass Ceramics in the Presence of a $\mathrm{Cr}_{2} \mathrm{O}_{3}$ Nucleant. Physics and Chemistry of Glasses, 40, 311-313.

[25] El-Shennawi, A.W., Omar, A.A. and Yamzawy, E.M.A. (2001) Effect of $\mathrm{Cr}_{2} \mathrm{O}_{3}, \mathrm{ZrO}_{2}$ and $\mathrm{LiF}$ on Nucleation and Crystallization of Nepheline Syenite-Dolomite GlassCeramic Compositions. Glass Science and Technology, 74, 317-323.

[26] Hudon, P., Jung, I.H. and Baker, D.R. (2004) Effect of Pressure on Liquid-Liquid Miscibility Gaps: A Case Study of the System $\mathrm{CaO}-\mathrm{SiO}_{2}, \mathrm{MgO}-\mathrm{SiO}_{2}$ and $\mathrm{CaMg}-$ $\mathrm{Si}_{2} \mathrm{O}_{6}-\mathrm{SiO}_{2}$. Journal of Geophysical Research, 109, B03207.

[27] Rezvani, M., Eftekhari-Yekta, B., Solati-Hashjin, M. and Marghussian, V.K. (2005) Effect of $\mathrm{Cr}_{2} \mathrm{O}_{3}, \mathrm{Fe}_{2} \mathrm{O}_{3}$ and $\mathrm{TiO}_{2}$ Nucleants on the Crystallization Behavior of $\mathrm{SiO}_{2}-$ $\mathrm{Al}_{2} \mathrm{O}_{3}-\mathrm{CaO}-\mathrm{MgO}\left(\mathrm{R}_{2} \mathrm{O}\right)$ Glass-Ceramics. Ceramics International, 31, 75-80.

[28] Sokolov, V.A. and Malysheva, T.Y. (2005) The Structure of Fusion-Cast HighChrome Oxide Refractories in the $\mathrm{Cr}_{2} \mathrm{O}_{3}-\mathrm{MgO}-\mathrm{Al}_{2} \mathrm{O}_{3}$ System. Refractories and Industrial Ceramics, 46, 127-131. https://doi.org/10.1007/s11148-005-0067-5

[29] Garza-Garcia, M., Lopez-Cuevas, J., Gutierrez-Chavarria, C.A., Rendon-Angeles, J.C. and Valle-Fuentos, J.F. (2007) Glass Constitution and Crystallization Characte- 
ristics of CaO-MgO- $\mathrm{Al}_{2} \mathrm{O}_{3}-\mathrm{SiO}_{2}$ Glass-Ceramic with $\mathrm{P}_{2} \mathrm{O}_{5}$ and $\mathrm{F}$ Additions. Boletín de la Sociedad Española de Cerámica y Vidrio, 46, 153-162.

[30] Taruta, S., Sakata, M., Yamaguchi, T. and Kitajima, K. (2008) Crystallization Process and Some Properties of Novel Transparent Machinable Calcium-Mica Glass-Ceramics. Ceramics International, 34, 75-79.

[31] Filipovich, V.N., Kalinina, A.M. and Sycheva, G.A. (1988) Glass Formation and Catalyzed Nucleation of Crystals. In: Glassy State Proceedings VIII All-Union Meeting on the Glassy State, Nauka, Leningrad, 87-96.

[32] Osborn, E.F. (1942) The System Wollastonite-Diopside-Anorthite. American Journal of Science, 240, 751-758. https://doi.org/10.2475/ajs.240.11.751

[33] Shelestak, L.J., Chavez, R.A. and Mackenzie, J.D. (1978) Glasses and Glass-Ceramics from Naturally Occurring $\mathrm{CaO}-\mathrm{MgO}-\mathrm{Al}_{2} \mathrm{O}_{3}-\mathrm{SiO}_{2}$ Materials. 1. Glass Formation and Properties. Journal of Non-Crystalline Solids, 27, 75-81.

[34] Shelestak, L.J., Chavez, R.A., Mackenzie, J.D. and Dunn, B. (1978) Glasses and Glass-Ceramics from Naturally Occurring Cao- $\mathrm{MgO}-\mathrm{Al}_{2} \mathrm{O}_{3}-\mathrm{SiO}_{2}$ Materials. 2. Crystallization Behavior. Journal of Non-Crystalline Solids, 27, 83-97.

[35] Kucharski, J. (1989) Directed Crystallization of Pyroxenes Inglass. Polska Akademia Nauk, Ceramika, 37, 43-78.

[36] Rincon, J.M., Gonzalez-Oliver, C.J.R. and James, P.F. (1992) Principles of Nucleation and Controlled Crystallization of Glasses. Polymer-Plastics Technology and Engineering, 31, 309-357. https://doi.org/10.1080/03602559208017751

[37] Tulyaganov, D.U. and Ismatov, A.A. (1993) Development and Application of Anorthite-Diopside Containing Glass-Ceramics. Ceramic Transactions, 29, 221224.

[38] Marghussian, V.K. and Niaki, M.H.D. (1995) Effects of Composition Changes on the Crystallization Behavior and Properties of $\mathrm{SiO}_{2}-\mathrm{Al}_{2} \mathrm{O}_{3}-\mathrm{CaO}-\mathrm{MgO}\left(\mathrm{Fe}_{2} \mathrm{O}_{3}-\mathrm{Na}_{2} \mathrm{O}-\right.$ $\mathrm{K}_{2} \mathrm{O}$ ) Glass-Ceramics. Journal of the European Ceramic Society, 15, 343-348.

[39] Ovecoglu, M.L., Kuban, B. and Ozer, H. (1997) Characterization and Crystallization Kinetics of a Diopside-Based Glass-Ceramic Developed from Glass Industry Raw Materials. Journal of the European Ceramic Society, 17, 957-962.

[40] Ovecoglu, M.L. (1998) Microstructural Characterization and Physical Properties of a Slag-Based Glass-Ceramic Crystallized at 950 and $1100{ }^{\circ} \mathrm{C}$. Journal of the European Ceramic Society, 18, 161-168.

[41] Duan, R.G. and Liang, K.M. (1998) A Study on the Crystallization of System CaO$\mathrm{Al}_{2} \mathrm{O}_{3}-\mathrm{SiO}_{2}$ System Glasses. Journal of Materials Processing Technology, 75, 235 239.

[42] Bryden, R.H., Goski, D.G. and Caley, W.F. (1999) Limealumina-Silica Processing Incorporating Minerals. Journal of the European Ceramic Society, 9, 1599-1604.

[43] Duca, V., Duca, M. and Benea, M. (2001) Crystallization of Some Glasses in CaO$\mathrm{MgO}-\mathrm{Al}_{2} \mathrm{O}_{3}-\mathrm{SiO}_{2}$ System. Key Engineering Materials, 213, 2081-2084.

[44] Feng, X., He, F. and Li, L. (2001) Research on Crystallization Behavior of CaO$\mathrm{Al}_{2} \mathrm{O}_{3}-\mathrm{SiO}_{2}$ System Glass-Ceramics. Journal of Wuhan University of TechnologyMaterials Science Edition, 23, 22-25.

[45] Tulyaganov, D.U., Ribeiro, M.J. and Labrincha, J.A. (2002) Development of GlassCeramics by Sintering and Crystallization of Fine Powders of Calcium-Magnesium-Aluminosilicate Glass. Ceramics International, 28, 515-520.

[46] Suzuki, M. and Tanaka, T. (2006) Prediction of Phase Separation in Silicate Glass for the Creation of Value-Added Materials from Waste Slag. ISIJ International, 46, 
1391-1395. https://doi.org/10.2355/isijinternational.46.1391

[47] Khater, G.A. and Idris, M.H. (2007) Effect of Glass Composition and Heat Treatment Parameters on Crystallization Behavior in the $\mathrm{Li}_{2} \mathrm{O}-\mathrm{BaO}-\mathrm{Al}_{2} \mathrm{O}_{3}-\mathrm{SiO}_{2}$ System. Physics and Chemistry of Glasses-European Journal of Glass Science and Technology Part B, 45, 141-145.

[48] Al-Harbi, O.A. (2007) Crystallization and Stability of Glass Ceramics within the $\mathrm{CaO}-\mathrm{Li}_{2} \mathrm{O}-\mathrm{SiO}_{2}$ System That Contain Wollastonite. Glass Technology-European Journal of Glass Science and Technology Part A, 48, 35-40.

[49] Tian, Q., Wang, X., Xu, L., Lin, X. and Gao, H. (2007) Glass Constitution and Crystallization Characteristics of $\mathrm{CaO}-\mathrm{MgO}-\mathrm{Al}_{2} \mathrm{O}_{3}-\mathrm{SiO}_{2}$ Glass-Ceramic with $\mathrm{P}_{2} \mathrm{O}_{5}$ and $\mathrm{F}$ Additions. Rare Metal Materials and Engineering, 36, 316-318.

[50] Garza-Garcia, M., Lopez-Cuevas, J., Gutierrez-Chavarria, C.A., Rendon-Angeles, J.C. and Valle-Fuentos, J.F. (2007) Study of a Mixed Alkaline-Earth Effect on Some Properties Glasses of the $\mathrm{CaO}-\mathrm{MgO}-\mathrm{Al}_{2} \mathrm{O}_{3}-\mathrm{SiO}_{2}$ System. Boletín de la Sociedad Española de Cerámica y Vidrio, 46, 153-162.

Submit or recommend next manuscript to SCIRP and we will provide best service for you:

Accepting pre-submission inquiries through Email, Facebook, LinkedIn, Twitter, etc. A wide selection of journals (inclusive of 9 subjects, more than 200 journals)

Providing 24-hour high-quality service

User-friendly online submission system

Fair and swift peer-review system

Efficient typesetting and proofreading procedure

Display of the result of downloads and visits, as well as the number of cited articles

Maximum dissemination of your research work

Submit your manuscript at: http://papersubmission.scirp.org/

Or contact jcpt@scirp.org 